\title{
Benchmark Structures and Binding Energies of Small Water Clusters with Anharmonicity Corrections
}

\author{
Berhane Temelso, Kaye A. Archer, and George C. Shields* \\ Dean's Office, College of Arts and Sciences, and Department of Chemistry, Bucknell University, Lewisburg, Pennsylvania 17837, \\ United States
}

Supporting Information

\section{ABSTRACT:}
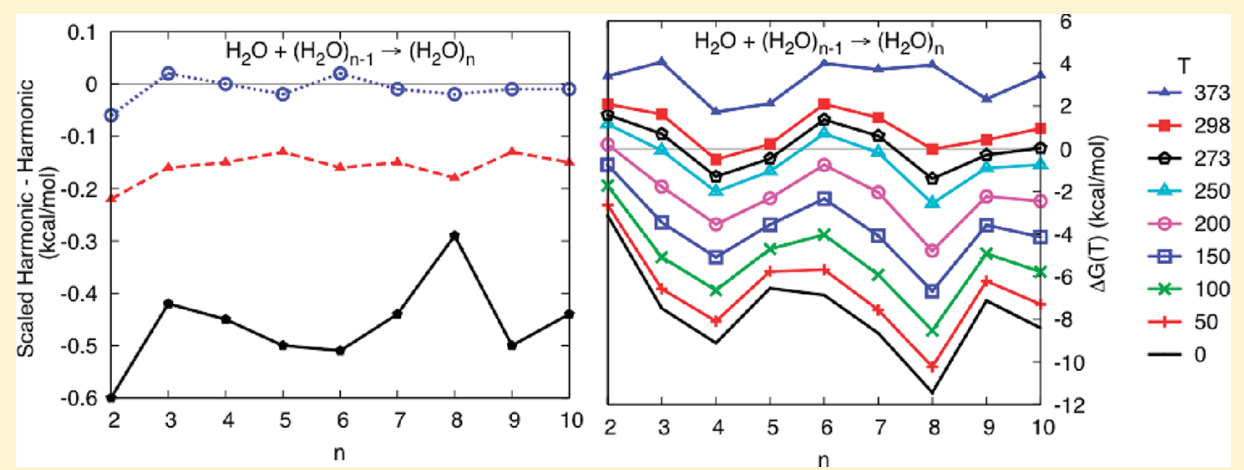

For $\left(\mathrm{H}_{2} \mathrm{O}\right)_{n}$ where $n=1-10$, we used a scheme combining molecular dynamics sampling with high level ab initio calculations to locate the global and many low lying local minima for each cluster. For each isomer, we extrapolated the RI-MP2 energies to their complete basis set limit, included a $\operatorname{CCSD}(\mathrm{T})$ correction using a smaller basis set and added finite temperature corrections within the rigid-rotor-harmonic-oscillator (RRHO) model using scaled and unscaled harmonic vibrational frequencies. The vibrational scaling factors were determined specifically for water clusters by comparing harmonic frequencies with VPT2 fundamental frequencies. We find the $\operatorname{CCSD}(\mathrm{T})$ correction to the RI-MP2 binding energy to be small $(<1 \%)$ but still important in determining accurate conformational energies. Anharmonic corrections are found to be non-negligble; they do not alter the energetic ordering of isomers, but they do lower the free energies of formation of the water clusters by as much as $4 \mathrm{kcal} / \mathrm{mol}$ at $298.15 \mathrm{~K}$.

\section{INTRODUCTION}

Water is a universal solvent and essential to life on Earth. Although immediately familiar, it has attracted great interest because of its many anomalous properties, including its unusually high boiling point, its low coefficient of thermal expansion, the fact that water contracts upon melting (density maximum is at $277 \mathrm{~K}$ ), and its nonmonotonic compressibility with temperature. Much experimental and theoretical work has been aimed at studying the structure and properties of water, both as a gas phase cluster and as liquid. ${ }^{1-67}$ Modeling water is difficult because the contribution that charge transfer, polarization, and electrostatics make to hydrogen bonding are still being debated. In addition, the dynamics of constant movement of water molecules within the liquid is extremely difficult to characterize both experimentally and theoretically.

Much computational work has focused on building empirical models that reproduce the properties of water in the bulk limit. ${ }^{68}$ Empirical models designed to reproduce thermodynamic values for bulk water oftentimes fail to describe smaller water clusters. The most commonly used rigid empirical model potentials like TIP$[3,4,5,] \mathrm{P}, \mathrm{SPC} / \mathrm{E}$ (see Guillot's ${ }^{69}$ review article and references therein) often give reasonable structures, but inaccurate binding energies. $^{70-73}$ Bandow and Hartke have shown that the TIP4P model produces qualitatively incorrect structures for clusters of $17-21$ waters where there is a transition from an all-surface to a monomer-centered structure. ${ }^{74}$ The performance of these model potentials for small water clusters has been compared against reliable second-order Møller-Plesset perturbation theory (MP2) calculations that have been extrapolated to the complete basis set (CBS) limit. The so-called ab initio based model potentials such as TTM- and ASP-type are fitted to quantum mechanical data and often designed to be flexible and polarizable. Therefore, they perform substantially better than empirical ones in describing small water clusters. ${ }^{42,74-77}$ The performance of both the ab initio and empirical model potentials have been evaluated by comparing to MP2/CBS results whenever possible. By 2002, more than 50 model potentials had been developed and none of them could describe all of the complex features of water correctly! ${ }^{69}$ Nevertheless, the elusive structure of water is one of the 125 outstanding problems in science $^{78}$ and remains a very active area of research. ${ }^{68,79,80}$

Received: July 20, 2011

Revised: $\quad$ September 9, 2011

Published: September 12, 2011 
Wave function and density functional (DFT) methods have been applied to small water clusters with varying degrees of success. Hartree-Fock (HF) theory generally performs poorly for noncovalently bonded systems. In a HF calculation, any given electron interacts with the average potential of the rest of the electrons, yet it is the instantaneous correlation of any given electron with other electrons that give rise to important effects like dispersion. Density functionals, although improving all the time, typically miss important dispersion interactions that are very important for water clusters. ${ }^{64,81}$ An n-body decomposition of the binding energy in water clusters shows that some of the agreement between many density functionals and benchmark ab initio data results from the fortuitous cancellation of errors in the 2-body and 3-body interaction terms. ${ }^{50,82}$ Adding an empirical van der Waals correction substantially improves the performance of DFT methods. ${ }^{50}$ Orbital localization schemes employed in local correlation methods like LMP2 largely mitigate the basis set superposition error (BSSE) problem ${ }^{82,83}$ but lead to underestimation of the correlation contribution to the interaction energy $^{83}$ and the nonadditive, many-body interactions ${ }^{84}$ that typically account for $20-30 \%$ of the binding energy in water clusters. $^{85,86}$

MP2 calculations with correlated basis sets, when extrapolated to the CBS limit, capture all of the important features of small water clusters. ${ }^{75,86-93}$ Extrapolations using the aug-cc-pVNZ basis sets of Dunning ${ }^{94,95}$ yield essentially identical results whether corrected for BSSE via the counterpoise correction ${ }^{96,97}$ or not. ${ }^{64,98}$ The MP2/CBS binding energies for $\left(\mathrm{H}_{2} \mathrm{O}\right)_{n=2-6,8}$ of Xantheas and co-workers have been the main benchmark against which most theoretical methods have been assessed. ${ }^{70,75,86,88,90-93,99,100}$ Even though it is the cheapest electron correlation method available, MP2 still scales as a fifth power with system size due to the cost of transforming four-index two-electron integrals from atomic orbital (AO) to molecular orbital (MO) basis. In RI-MP2, resolution-of-the-identity ( $\mathrm{RI}$ ) approximation is applied to the four-index two electron integrals to write them in terms of twoand three-index two electron integrals that are cheaper to compute and transform. ${ }^{101,102}$ As Sherrill et al. recently demonstrated for the S22 benchmark database of weakly bound dimers, the RI approximation of the two-electron integrals and dual-basis (DB) approximation of the HF energy lead to very small errors in the interaction energy of these dimers. ${ }^{103}$ Similarly, Kossmann et al. have shown that using the RI approximation for the Coulomb part and a seminumerical "chain of spheres" (COSX) for the exchange part of the HF energy leads to remarkable computational savings without significantly compromising accuracy. ${ }^{104,105}$ When used with a good auxiliary basis like those developed by Weigend et al., ${ }^{106}$ RI-MP2 is able to give energies in excellent agreement with MP2 at a significantly lower computational cost. We have used the RI-MP2 method to calculate RI$\mathrm{MP} 2 / \mathrm{CBS}$ binding and conformational energies for the most relevant isomers of $\left(\mathrm{H}_{2} \mathrm{O}\right)_{n=1-10}$. For the lowest energy structures, we extrapolated the RI-MP2/aug-cc-pV[DTQ $] \mathrm{Z}$ binding energies to the CBS limit and included a coupled cluster singles doubles and perturbative triples $[\operatorname{CCSD}(\mathrm{T})]$ correction to the RI-MP2/CBS energies using the aug-cc-pVDZ basis set. Furthermore, we have computed thermodynamic corrections using RIMP2/aug-cc-pVDZ harmonic vibrational frequencies and scaled harmonic frequencies using multiplicative factors developed specifically for water clusters. 107

In this paper, we combine molecular dynamics sampling with quantum mechanical minimizations to determine the low energy isomers of small water clusters of sizes $2-10$. We present RIMP2/CBS binding and conformational energies and include corrections for higher-order electron correlations using CCSD(T) and anharmonicity using frequency scaling factors designed specifically for water clusters. We use the binding Gibbs free energies to assess the formation of water clusters at different temperatures.

\section{METHODOLOGY}

Initial structures (see Figure 1) for $\left(\mathrm{H}_{2} \mathrm{O}\right)_{n=2-6,8}$ were taken from our previous work ${ }^{108}$ as well as other literature. ${ }^{109-111}$ For $\left(\mathrm{H}_{2} \mathrm{O}\right)_{n=7,9,10}$, we previously ran 10 nanosecond gas-phase molecular dynamics simulations using AMBER 9 at $200(n=7,9)$ or $250(n=10) \mathrm{K}$ and extracted $200(n=7,9)$ or $300(n=10)$ structures. The lowest energy isomers were determined using MP2/aug-cc-pVDZ//MP2/6-31G* Gibbs free energies. In this work we use the resolution-of-the-identity MP2 (RI-MP2) method $^{101,102}$ with Dunning's augmented correlation-consistent basis sets (aug-cc-pVNZ, $N=\mathrm{D}, \mathrm{T}, \mathrm{Q})^{94,95}$ and corresponding auxiliary basis sets ${ }^{106}$ to obtain RI-MP2/CBS structures and binding energies. We denote Dunning's aug-cc-pVNZ $(N=\mathrm{D}, \mathrm{T}$, Q) basis sets by aVNZ (N=D, T, Q) for the sake of brevity. Low energy structures from our previous work were fully optimized at the RI-MP2/aVDZ level using analytic gradients ${ }^{112}$ with strict convergence criteria on energies $\left(\Delta E<1 \times 10^{-7}\right.$ a.u. $)$, gradients (rms gradient $<3 \times 10^{-5}$ a.u./ $\AA$ ), and geometries (rms displacement $<6 \times 10^{-4} \AA$ ). The oxygen 1 s orbitals were excluded from all electron correlation calculations by invoking the frozen core approximation.

As shown by Xantheas et al. ${ }^{91}$ the geometries of small water clusters do not change substantially as one uses basis sets larger than aVDZ in the optimization stage. Our investigation of the sensitivity of binding energies to geometries computed using RIMP2/aVTZ and RI-MP2/aVTZ//RI-MP2//aVDZ shows that the difference is less than $0.1 \mathrm{kcal} / \mathrm{mol}$ for $\left(\mathrm{H}_{2} \mathrm{O}\right)_{n=2-6}$. Thus we compute large basis set, single-point energies, of the clusters using RI-MP2/aVDZ optimized geometries. The RI-MP2 complete basis set limit is estimated using two extrapolation schemes.

The 4-5 inverse polynomial extrapolation ${ }^{90,113}$ has been used extensively for water clusters

$$
E_{C B S}^{R I-M P 2}=E_{N}^{R I-M P 2}+\frac{b}{(N+1)^{4}}+\frac{c}{(N+1)^{5}}
$$

where $\Delta E_{\mathrm{N}}^{\mathrm{RIMP} 2}$ is the RI-MP2/aVNZ//RI-MP2/aVDZ energy, $\Delta E_{\mathrm{CBS}}^{\mathrm{RIMP} 2}$ is the extrapolated RI-MP2/CBS energy, $N$ is the largest angular momentum number for the aVNZ basis set $(N=2-5$ for $N=\mathrm{D}, \mathrm{T}, \mathrm{Q}$, respectively), and $b$ and $c$ are fitting parameters. ${ }^{113,114}$ Least-squares fitting of the RI-MP2/aVNZ//RI-MP2/aVDZ ( $N=$ $\mathrm{D}, \mathrm{T}, \mathrm{Q}, 5)$ energies to eq 1 yields the RI-MP2/CBS energy for a given cluster.

The extrapolation of the SCF energy using an exponential function [eq 2] and the RI-MP2 correlation energy using an inverse cubic function [eq 3] has been advocated by Halkier et al. ${ }^{115,116}$

$$
\begin{aligned}
& E_{\mathrm{CBS}}^{\mathrm{SCF}}=E_{\mathrm{N}}^{\mathrm{SCF}}+B e^{-A N} \\
& E_{\mathrm{CBS}}^{\mathrm{corr}}=\frac{N^{3} E_{\mathrm{N}}^{\mathrm{corr}}-(N-1)^{3} E_{N-1}^{\mathrm{corr}}}{N^{3}-(N-1)^{3}} \\
& E_{\mathrm{CBS}}^{\mathrm{RI}-\mathrm{MP} 2}=E_{\mathrm{CBS}}^{\mathrm{SCF}}+E_{\mathrm{CBS}}^{\mathrm{corr}}
\end{aligned}
$$




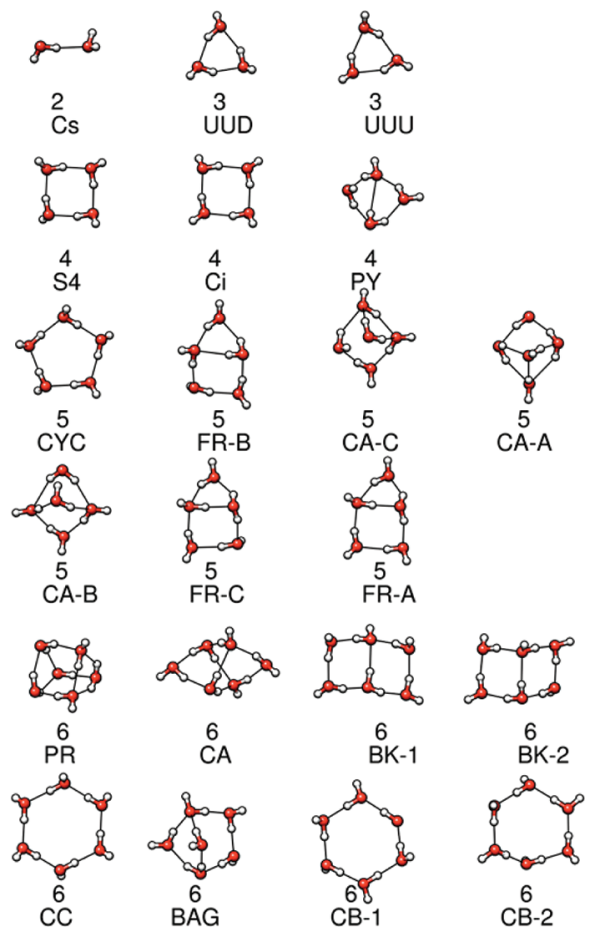

Figure 1. RI-MP2/CBS low energy isomers of $\left(\mathrm{H}_{2} \mathrm{O}\right)_{n=2-6}$ sorted in order of increasing size and electronic energy.

Here $A$ and $B$ are fitting parameters $E_{\mathrm{CBS}}^{\mathrm{SCF}}, E_{\mathrm{CBS}}^{\mathrm{corr}}$, and $E_{\mathrm{CBS}}^{\mathrm{RI}-\mathrm{MP} 2}$ are the complete basis set SCF, RI-MP2 correlation and total energies. The complete basis set SCF energy is determined using the aug-cc$\operatorname{pVNZ}(N=\mathrm{D}, \mathrm{T}, \mathrm{Q})$ basis sets while the extrapolated correlation energy is derived from the aug-cc-pVNZ $(N=\mathrm{T}, \mathrm{Q})$ correlation energies. Previous works implied that the difference between counterpoise (CP) corrected and uncorrected binding energies is smallest when the 4-5 inverse polynomial extrapolation scheme is used. $^{51,91,114,117}$ As finite basis MP2 calculations on weakly bound clusters suffer from BSSE as well as basis set incompleteness, it is important to extrapolate to the basis set limit and correct for BSSE. For four water clusters ranging from the dimer to the pentamer, we used counterpoise correction to obtain BSSE-free binding energies. We then applied the 4-5 inverse polynomial and conventional extrapolation schemes to determine which one gives the quickest convergence of the CP corrected and uncorrected binding energies toward the basis set limit.

The importance of higher-order electron correlation past the MP2 level of theory has been examined by comparing the $\operatorname{CCSD}(\mathrm{T}) / \mathrm{aVDZ}$ and MP2/aVDZ single point energies at the RI-MP2/aVDZ optimized geometry. The higher-order electron correlation correction is defined as

$$
\delta_{\mathrm{MP2}}^{\mathrm{CCSD}(\mathrm{T})}=E_{\mathrm{CCSD}(\mathrm{T}) / \mathrm{aVDZ} / / \mathrm{RI}-\mathrm{MP} 2 / \mathrm{aVDZ}}-E_{\mathrm{MP} 2 / \mathrm{aVDZ} / / \mathrm{RI}-\mathrm{MP} 2 / \mathrm{aVDZ}}
$$

The basis set dependence of $\delta_{\mathrm{MP2}}^{\mathrm{CCSD}(\mathrm{T})}$ is investigated by calculating $\operatorname{CCSD}(\mathrm{T}) / \mathrm{aVTZ}$ and MP2/aVTZ energies on RI-MP2/ aVTZ geometries. As shown by Jurecka and Hobza, ${ }^{118}$ the basis set sensitivity of the higher-order electron correlation correction is typically very small when using basis sets of cc-pVDZ or better quality. Therefore we approximated the $\operatorname{CCSD}(\mathrm{T}) / \mathrm{CBS}$ binding energies as a sum of the RI-MP2/CBS binding energies and the higher-order electron correlation correction using eq 6

$$
E_{\mathrm{CBS}}^{\mathrm{CCSD}(\mathrm{T})}=E_{\mathrm{CBS}}^{\mathrm{RI}-\mathrm{MP2}}+\delta_{\mathrm{MP} 2}^{\mathrm{CCSD}(\mathrm{T})}
$$

Zero-point corrected energies $(E(0))$, energies including finite temperature corrections $(E(T))$, enthalpies $(H(T))$, and Gibbs free energies $(G(T))$, were calculated by combining the RIMP2/aVDZ thermodynamic corrections with the RI-MP2/CBS and $\operatorname{CCSD}(\mathrm{T}) / \mathrm{CBS}$ electronic energies. Harmonic vibrational frequencies were computed numerically at the RI-MP2/aVDZ level using central differences with step sizes of $0.005 \AA$. Thermodynamic corrections are traditionally calculated from canonical partition functions with the assumption that the translational, vibrational and rotational degrees of freedom can be sufficiently treated in the framework of an ideal gas, harmonic oscillator and rigid rotor approximations. The harmonic approximation of vibrational modes is particularly problematic in the case of low frequency, large amplitude intermolecular modes of weakly bound systems like our water clusters. We have partially corrected for the deviation from harmonic behavior by scaling the harmonic vibrational frequencies to match anharmonic ones. In another paper, ${ }^{107}$ we have determined multiplicative scaling factors for the ZPVE, and the frequencies input into $\Delta H_{\mathrm{vib}}(T)$ and $S_{\text {vib }}(T)$ expressions specifically for water clusters using MP2/ aVDZ. At $298.15 \mathrm{~K}$, the optimal scaling factors for the ZPVE and vibrational frequencies entering the expressions for $\Delta H_{\mathrm{vib}^{-}}$ $(298.15 \mathrm{~K})$ and $S_{\text {vib }}(298.15 \mathrm{~K})$ are $0.976,0.868$, and 0.844 , respectively. The scaling factors at other temperatures are shown in Table S2, S3, and S4 of the Supporting Information.

Because of the small energetic differences, we have reported the energies to the 100th decimal place to preserve 10th place information; the error bars in this method are expected to be on the order of many 10 ths of a $\mathrm{kcal} / \mathrm{mol}$. For the ith isomer of $\left(\mathrm{H}_{2} \mathrm{O}\right)_{n}, \Delta E_{\mathrm{e}}^{n_{i}}, \Delta \Delta E_{\mathrm{e}}^{n_{i}}, \Delta G_{T}^{n_{i}}$ and $\Delta \Delta G_{T}^{n_{i}}$ are defined as

$$
\begin{aligned}
& \Delta E_{\mathrm{e}}^{n_{i}}=E_{\mathrm{e}}^{n_{i}}-n_{i} E_{\mathrm{e}}^{1} \\
& \Delta \Delta E_{\mathrm{e}}^{n_{i}}=\Delta E_{\mathrm{e}}^{n_{i}}-\min _{i}\left\{\Delta E_{\mathrm{e}}^{n_{i}}\right\} \\
& \Delta G_{\mathrm{T}}^{n_{i}}=G_{\mathrm{T}}^{n_{i}}-n_{i} G_{\mathrm{T}}^{1} \\
& \Delta \Delta G_{\mathrm{T}}^{n_{i}}=\Delta G_{\mathrm{T}}^{n_{i}}-\min _{i}\left\{\Delta G_{\mathrm{T}}^{n_{i}}\right\}
\end{aligned}
$$

The presence of many stable structures within available thermal energy $\left(k_{\mathrm{b}} T\right)$ suggests that a meaningful free energy for a cluster of size $n$ must include a weighted account of all isomers of $\left(\mathrm{H}_{2} \mathrm{O}\right)_{n}$. We weigh the contribution of each low energy isomer by its Boltzmann factor $\left(x_{n_{i}}\right)$ to get the Boltzmann averaged free energy $\left(\Delta G_{\mathrm{T}}^{n}\right)$

$$
\begin{gathered}
x_{n_{i}}=\frac{\mathrm{e}^{-\Delta \Delta G_{\mathrm{T}}^{n_{i}} / k_{\mathrm{b}} T}}{\sum_{n_{i}} \mathrm{e}^{-\Delta \Delta G_{\mathrm{T}}^{n_{i}} / k_{\mathrm{b}} T}} \\
\Delta G_{\mathrm{T}}^{n}=\sum_{n_{i}} x_{n_{i}} \Delta G_{\mathrm{T}}^{n_{i}}
\end{gathered}
$$

All calculations used the ORCA 2.8.0 package (http://www.thch. uni-bonn.de/tc/orca/), and the graphics were generated using Chimera 1.5. ${ }^{119}$

\section{RESULTS}

The 38 water clusters included in this study are shown in Figures 1 and 2 in order of increasing electronic energy. Figure 3 illustrates that even using the large aVQZ basis set does not give binding energies that are sufficiently converged. Thus, it is 
imperative that one uses a basis set extrapolation scheme. Table 1 shows that the RI-MP2/aVNZ $(N=\mathrm{D}, \mathrm{T}, \mathrm{Q})$ binding energies converge slowly and monotonically toward the RI-MP2/CBS values calculated using Halkier's coventional extrapolation and 4-5 inverse polynomial schemes. Both schemes compare fairly well with the benchmark MP2/CBS binding energies of Xantheas et al. ${ }^{91,117}$ At the basis set limit, the CP corrected and uncorrected binding energies should ideally converge to the same value. Figure 5 explores the convergence of the $\mathrm{CP}$ corrected and uncorrected binding energies. It is clear that the conventional extrapolation does not yield as good a convergence as the 4-5 inverse polynomial extrapolation. The results in Figure 4 reveal that the 4-5 inverse polynomial extrapolation gives binding energies that are a lot closer to the benchmark MP2/CBS values while the conventional scheme leads to larger differences.

The effect of higher order electron correlation past MP2 on the binding energy of water clusters is shown for some of the clusters in this study in Figure 6. Overall, this correction is small compared to the binding energy of these clusters, but it is not negligible. The correction affects conformational energies substantially in that it generally stabilizes more three-dimensional structures over planar and quasi-planar ones. The bottom of Figure 6 provides an explanation why the $\operatorname{CCSD}(\mathrm{T})$ correction is small; there is very little multireference character in these water clusters as can be seen from the $T_{1}$ diagnostic value that does not change much with increasing water cluster size.

A comparison of the harmonic, scaled harmonic and anharmonic ZPVE, $\Delta H_{\text {vib }}(298.15 \mathrm{~K})$ and $S_{\text {vib }}(298.15 \mathrm{~K})$ for 11 water clusters is shown in Figure 7. The anharmonic corrections are calculated using VPT2/MP2/aVDZ fundamental frequencies and employ an approximation of the true $\mathrm{ZPVE}^{120}$ and thermodynamic corrections via simple perturbation theory. ${ }^{121}$ It validates the use of scaled harmonic frequencies to approximate the anharmonic corrections. Table 2 and Table 3 show the harmonic and scaled harmonic binding energies and enthalpies for all water clusters in this study. For the water hexamer and heptamer, there are eight and eleven isomers, respectively, that are very close in energy. The global minimum changes dynamically as temperature increases. The relative Gibbs free energies of the hexamer and heptamer isomers as a function of temperature are shown in Figure 8 and Figure 9.

The Boltzmann averaged binding free energy for each cluster size is tabulated for both the stepwise addition of a water monomer to an existing cluster (Table 4) as well as the formation of a cluster from many water monomers (Table 5). Lastly, the effect of anharmonic corrections on Boltzmann averaged $\Delta \mathrm{H}(0 \mathrm{~K})$, $\Delta H(298.15 \mathrm{~K})$, and $\Delta G(298.15 \mathrm{~K})$ is illustrated in Figure 11. Anharmonic corrections are particularly large for $\Delta G(298.15 \mathrm{~K})$ because of entropic effects.

\section{DISCUSSION}

4.1. Basis Set Extrapolation Schemes. As is well-known, interaction energies of noncovalently bonded systems are difficult to calculate because of basis set incompleteness and basis set superposition errors. The failure of Gaussian basis sets to properly describe the electronic Coulumb cusp leads to slow convergence of the SCF and correlation energy with increasing basis set size. BSSE plagues the calculation of binding energies particularly when using MP2 with a small basis set. One can address the two issues by extrapolating the energy to the CBS
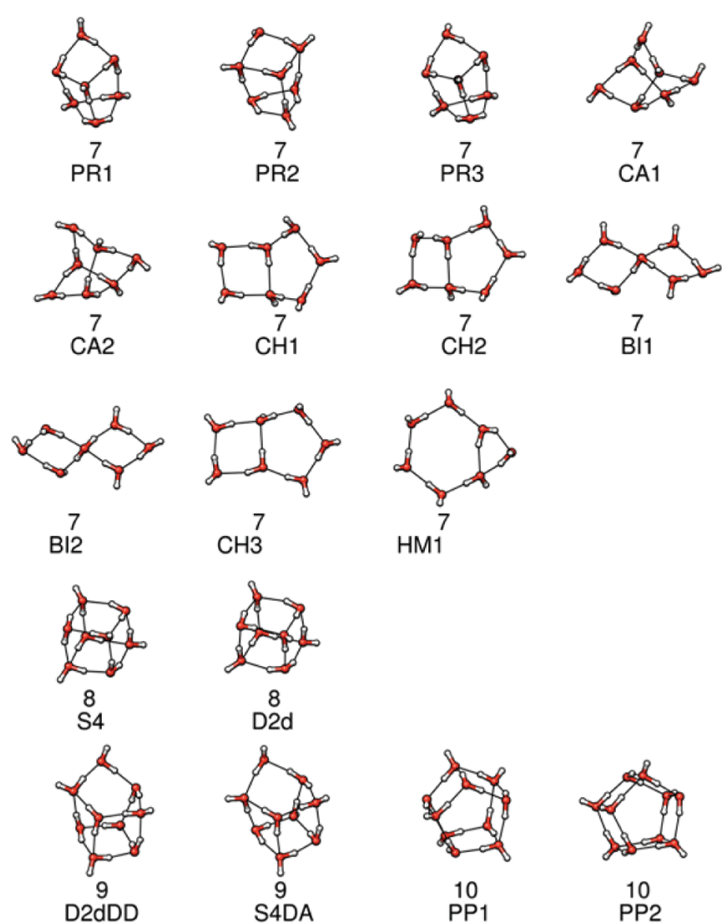

$\mathrm{CH} 3$

$\mathrm{HM} 1$
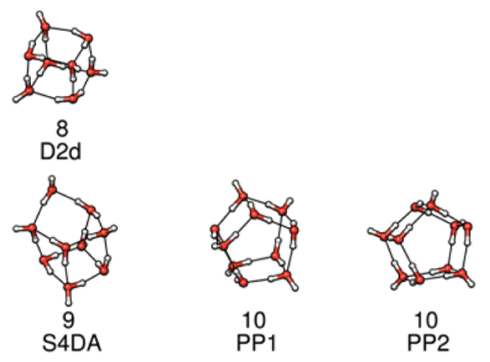

Figure 2. RI-MP2/CBS low energy isomers of $\left(\mathrm{H}_{2} \mathrm{O}\right)_{n=7-10}$ sorted in order of increasing size and electronic energy.

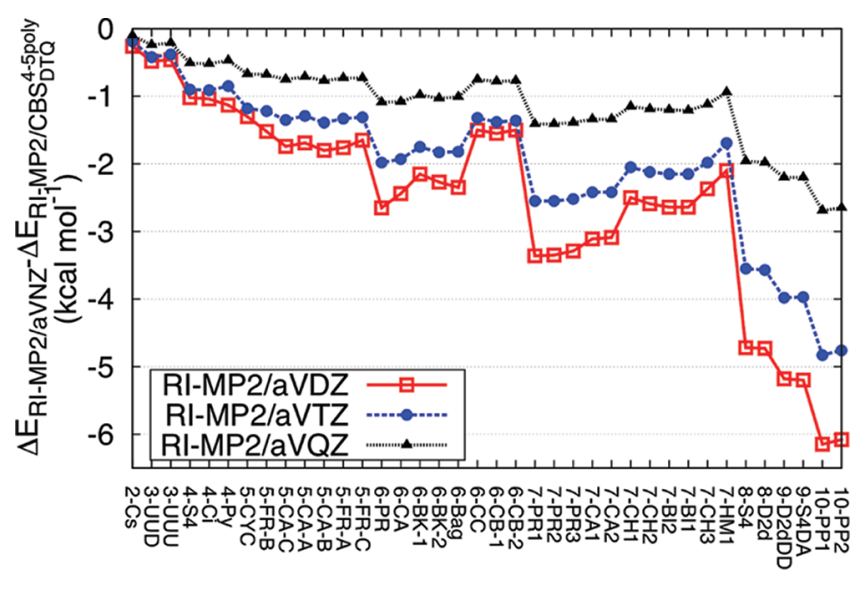

Figure 3. Errors in RI-MP2/aVNZ//aVDZ $(N=\mathrm{D}, \mathrm{T}, \mathrm{Q})$ binding energies for $\left(\mathrm{H}_{2} \mathrm{O}\right)_{n=2-10}$ relative to the RI-MP2/CBS values extrapolated using the 4-5 inverse polynomial scheme (eq 1 ).

limit and employing counterpoise correction. Figure 3 compares the errors in the RI-MP2 binding energies with various basis sets relative to the RI-MP2/CBS ${ }_{\mathrm{DTQ}}^{4-5 \text { poly }}$ values. Table 1 shows that as the number of basis functions increases from aVDZ (41 per monomer) to aVTZ (92 per monomer) to aVQZ (172 per monomer), the mean absolute error (MAE) in the binding energies relative to the Xantheas' MP2/CBS value decreases from 2.18 to 1.74 to $0.99 \mathrm{kcal} / \mathrm{mol}$ for a set of 10 water clusters. Such large errors are non-negligible for a benchmark study of binding energy of these hydrogen-bonded systems. The only way to ensure accurate binding energies is to employ basis set extrapolation schemes.

The conventional extrapolation defined in eqs $2-4$ requires energy calculations using three and two basis sets of consecutive 
Table 1. Comparison of RI-MP2/aVNZ ( $=$ D,T,Q,5) and RI-MP2/CBS Binding Energies with Benchmark ${ }^{e, f}$ MP2/CBS Values for $\left(\mathrm{H}_{2} \mathrm{O}\right)_{n=2-6,8}{ }^{a}$

\begin{tabular}{|c|c|c|c|c|c|c|c|c|c|}
\hline \multirow[b]{2}{*}{$\left(\mathrm{H}_{2} \mathrm{O}\right)_{n}{ }^{b}$} & \multicolumn{8}{|c|}{ RI-MP2 } & \multirow[b]{2}{*}{ MP2 CBS } \\
\hline & $\mathrm{aVDZ}$ & aVTZ & aVQZ & aV5Z & $\mathrm{CBS}_{\text {DTQ }}^{\text {Conv }}{ }^{c}$ & $\mathrm{CBS}_{\mathrm{DTQ}}^{4-\text { Spoly } d}$ & $\mathrm{CBS}_{\mathrm{TQS}}^{\text {Conv } c}$ & $\mathrm{CBS}_{\mathrm{DTQS}}^{4-\text { Spoly } d}$ & \\
\hline $2-\left(C_{s}\right)$ & -5.26 & -5.19 & -5.10 & -5.08 & -5.06 & -5.00 & -5.06 & -5.03 & $-4.97^{e}$ \\
\hline 3-UUD & -16.20 & -16.14 & -15.96 & -15.81 & -15.90 & -15.72 & -15.67 & -15.67 & $-15.82^{e}$ \\
\hline 3-UUU $\left(C_{3}\right)$ & -15.63 & -15.55 & -15.38 & -15.25 & -15.33 & -15.17 & -15.13 & -15.12 & \\
\hline $4-\left(S_{4}\right)$ & -28.66 & -28.54 & -28.15 & -27.92 & -27.94 & -27.64 & -27.72 & -27.63 & $-27.63^{e}$ \\
\hline 4- $\left(C_{i}\right)$ & -27.84 & -27.71 & -27.32 & -27.11 & -27.09 & -26.80 & -26.94 & -26.81 & \\
\hline 4-PY & -24.94 & -24.66 & -24.28 & -24.03 & -24.14 & -23.81 & -23.81 & -23.76 & \\
\hline 5-CYC & -37.65 & -37.52 & -37.02 & -36.77 & -36.74 & -36.38 & -36.53 & -36.39 & $-36.31^{e}$ \\
\hline 6-PR & -48.67 & -48.00 & -47.11 & -46.62 & -46.71 & -46.02 & -46.21 & -46.01 & $-45.86^{e}$ \\
\hline 6-CA & -48.42 & -47.91 & -47.06 & -46.62 & -46.64 & -45.98 & -46.27 & -46.02 & $-45.79^{e}$ \\
\hline 6-BK-1 & -47.92 & -47.52 & -46.75 & -46.31 & -46.33 & -45.77 & -45.94 & -45.75 & $-45.61^{e}$ \\
\hline $6-\mathrm{CC}\left(S_{6}\right)$ & -46.59 & -46.41 & -45.84 & -45.49 & -45.49 & -45.09 & -45.20 & -45.06 & $-44.86^{e}$ \\
\hline $8-\left(D_{2 d}\right)$ & -77.33 & -76.17 & -74.58 & -73.84 & -73.75 & -72.60 & -73.22 & -72.75 & $-72.7^{f}$ \\
\hline $8-\left(S_{4}\right)$ & -77.36 & -76.19 & -74.60 & -73.87 & -73.78 & -72.64 & -73.25 & -72.79 & $-72.7^{f}$ \\
\hline $\mathrm{MAE}^{g}$ & 1.66 & 1.28 & 0.63 & 0.29 & 0.31 & 0.19 & & 0.17 & 0.31 \\
\hline $\mathrm{MAE}^{h}$ & 1.82 & 1.44 & 0.80 & 0.46 & 0.47 & 0.05 & 0.17 & & 0.11 \\
\hline $\mathrm{MAE}^{i}$ & 2.18 & 1.74 & 0.99 & 0.61 & 0.61 & 0.11 & 0.31 & 0.11 & \\
\hline
\end{tabular}

${ }^{a}$ All binding energies are computed at the RI-MP2/aVDZ geometry and reported in $\mathrm{kcal} / \mathrm{mol} .{ }^{b}$ Point group symmetries shown in paranthesis for structures with symmetry higher that $C_{1} \cdot{ }^{c}$ Extrapolated using the conventional scheme shown in eqs $2-4$. ${ }^{d}$ Extrapolated using the 4-5 inverse polynomial shown in eq $1 .{ }^{e}$ Reference $91 .{ }^{f}$ Reference $117 .{ }^{g}$ Mean absolute error relative to RI-MP2/CBS $\mathrm{TQn}_{\mathrm{T} 5}^{\text {Conv }}$ values in column $8 .{ }^{h}$ Mean absolute error relative to RI-MP2/CBS ${ }_{\mathrm{DTQS}}^{4-5 \text { poly }}$ values in column 9. ${ }^{i}$ Mean absolute error relative to MP2/CBS values in column 10.

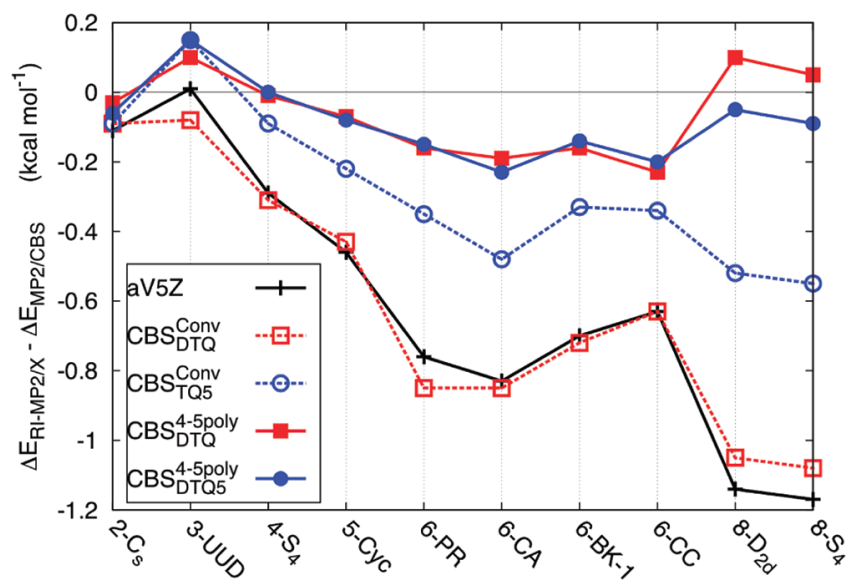

Figure 4. Difference between MP2/CBS 91,117 and RI-MP2/CBS binding energies extrapolated using Halkier's conventional scheme (open dash) and the 4-5 inverse polynomial scheme (filled solid) with aVDZ, aVTZ, aVQZ, and aV5Z basis sets.

cardinal numbers for the SCF and correlation energies, respectively. ${ }^{115,116}$ The $\mathrm{CBS}_{\mathrm{DTQ}}^{\mathrm{Conv}}$ binding energy is determined by extrapolating the aVDZ, aVTZ and aVQZ SCF energies using eq 2 and the aVTZ and aVQZ correlation energies using eq 3. The $\mathrm{CBS}_{\mathrm{TQ}}^{\mathrm{Conv}}$ binding energy is calculated using the aVTZ, aVQZ and aV5Z SCF energies and the aVQZ and aV5Z correlation energies. The 4-5 inverse polynomial extrapolation scheme defined in eq 1 has been advocated by Xantheas et al. ${ }^{91,117}$ in their benchmark works and used routinely in ab initio water clusters studies. ${ }^{51}$ The total energies can be extrapolated using the aVDZ, aVTZ and aVQZ single point energies $\left(C B S_{\mathrm{DTQ}}^{4-5 \text { poly }}\right)$ or also including aV5Z( $\left.\mathrm{CBS}_{\mathrm{DTQ}}^{4-5 \text { poly }}\right)$.

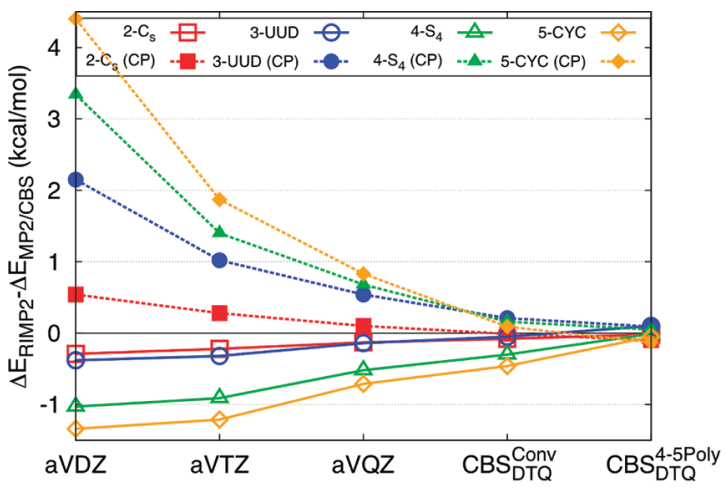

Figure 5. Convergence of the RI-MP2 counterpoise corrected and uncorrected binding energies toward the basis set limit for $\left(\mathrm{H}_{2} \mathrm{O}\right)_{n=2-5}$. $\mathrm{CBS}_{\mathrm{DTQ}}^{\mathrm{Conv}}$ represents the CBS limit computed using eqs $2-4$, whereas $\mathrm{CBS}_{\mathrm{DTO}}^{4-5 p o l y}$ employs the 4-5 inverse polynomial extrapolation defined in eq 1 . The binding energies are compared against the MP2/CBS values from refs 91 and 117.

In evaluating the extrapolation schemes, we have compared $\mathrm{RI}-\mathrm{MP} 2 / \mathrm{CBS}_{\mathrm{DTQ}}^{\mathrm{Conv}}$ and RI-MP2/CBS $4-5$ poly binding energies with RI-MP2/CBS $\mathrm{TQ5}$ and RI-MP2/CBS 4 DTQ5 5 analogs as well as Xantheas' MP2/CBS values for 10 water clusters. The MAE of the RI-MP2/CBS $\mathrm{Conv}$ binding energies relative to the RI-MP2/ $\mathrm{CBS}_{\mathrm{TQ5}}^{\text {Conv }}, \mathrm{RI}-\mathrm{MP} 2 / \mathrm{CBS}_{\mathrm{DTQ5}}^{4-5 \text { poly }}$, and Xantheas' MP2/CBS values are $0.31,0.47$, and $0.61 \mathrm{kcal} / \mathrm{mol}$, respectively. The RI-MP2/ $\mathrm{CBS}_{\mathrm{DTQ}}^{\mathrm{Conv}}$ binding energies are almost identical to the MAE of the RI-MP2/aV5Z binding energies (see Table 1 and Figure 4). That suggests the conventional extrapolation scheme employing the aVDZ, aVTZ and aVQZ basis sets does an excellent job of reproducing aV5Z quality binding energies. Unfortunately, the RI-MP2 binding energy is not sufficiently converged even when 


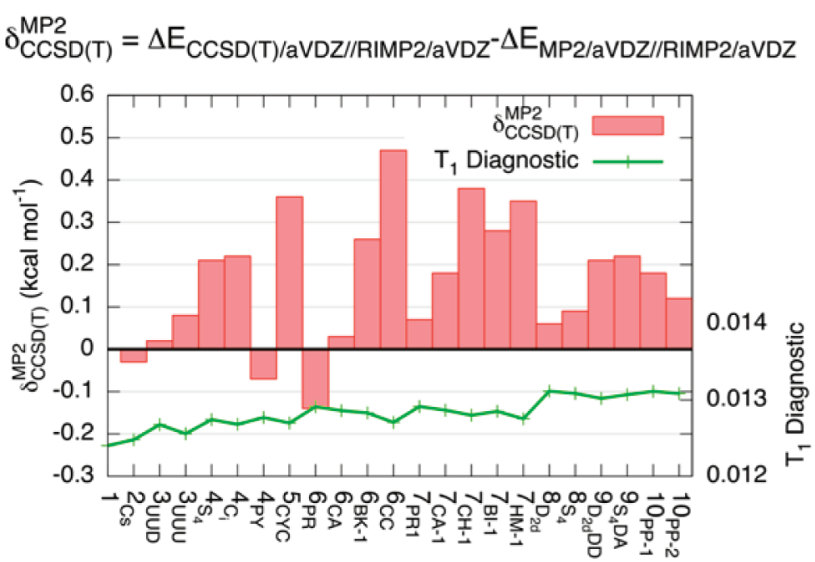

Figure 6. $\operatorname{CCSD}(\mathrm{T})$ correction to the RI-MP2 binding energy for water clusters (top) and the $T_{1}$ diagnostic values of the CCSD/aVDZ wave function at the RI-MP2/aVDZ geometries for $\left(\mathrm{H}_{2} \mathrm{O}\right)_{n=2-10}$ (bottom).

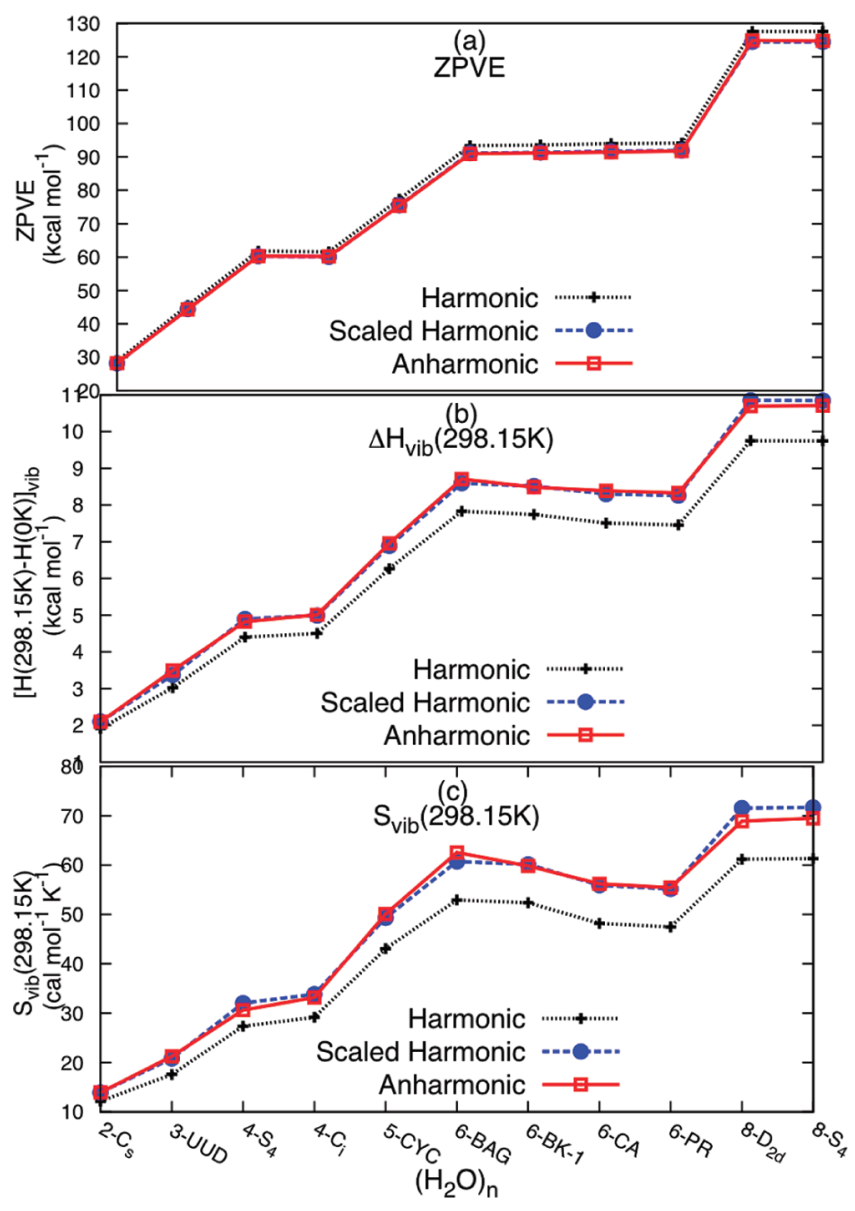

Figure 7. Comparison of the harmonic, scaled harmonic and anharmonic ZPVE, $\Delta H_{\text {vib }}(298.15 \mathrm{~K})$, and $S_{\text {vib }}(298.15 \mathrm{~K})$ for 11 water clusters. Scaling factors for ZPVE and vibrational frequencies entering the expressions for $\Delta H_{\text {vib }}(298.15 \mathrm{~K})$ and $S_{\text {vib }}(298.15 \mathrm{~K})$ are $0.976,0.868$, and 0.844 , respectively.

using a large aV5Z basis set, as shown in previous works. ${ }^{91,117}$ Including the aV5Z calculations in the conventional extrapolation scheme (RI-MP2/CBS ${ }_{\mathrm{TQ}}^{\mathrm{Conv}}$ ) leads to MAEs of 0.17 and

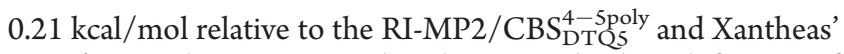
MP2/CBS values, respectively. The mean absolute difference of about $0.3 \mathrm{kcal} / \mathrm{mol}$ between the RI-MP2/CBS DTQ $^{\text {Conv }}$ and RI-MP2/ $\mathrm{CBS}_{\mathrm{TQ}}^{\mathrm{Conv}}$ further reinforces that the binding energy is not sufficiently converged using the RI-MP2/CBS $\mathrm{DTQ}_{\mathrm{DT}}^{\mathrm{Conv}}$ extrapolation. The 4-5 inverse polynomial extrapolation $\left(\mathrm{CBS}_{\mathrm{DTQ}}^{4-5 p o l y}\right)$ has much smaller MAEs relative to the RI-MP2/CBS $\mathrm{TON}_{\mathrm{TO}}^{\mathrm{Con}}(0.19 \mathrm{kcal} / \mathrm{mol})$, RI-MP2/CBS $4-5$ poly $(0.05 \mathrm{kcal} / \mathrm{mol})$, and Xantheas' MP2/ CBS $(0.11 \mathrm{kcal} / \mathrm{mol})$ values. Figure 4 shows that the binding energies extrapolated using the 4-5 inverse polynomial scheme ( $\mathrm{CBS}_{\mathrm{DTO}}^{4-5 \text { soly }}$ and $\mathrm{CBS}_{\mathrm{DTO5}}^{4-5 \text { poly }}$ ) are much closer to benchmark MP2/ CBS benchmarks ${ }^{91,117}$ than those determined using the conventional extrapolation ( $\mathrm{CBS}_{\mathrm{DTQ}}^{\text {Conv }}$ and $\left.\mathrm{CBS}_{\mathrm{TQ}}^{\text {Conv }}\right)$.

Further support for the 4-5 inverse polynomial extrapolation scheme can be found by looking at the convergence of the counterpoise corrected and uncorrected binding energies. By definition, the two should converge to the same CBS limit with increasing basis set size. Figure 5 demonstrates that both the $\mathrm{CP}$ corrected and uncorrected energies converge quickest to the MP2/CBS benchmark when extrapolated using the 4-5 inverse polynomial scheme than the conventional extrapolation. Halkier et al. ${ }^{122}$ have studied the basis set convergence of the interaction energy of hydrogen bonded systems including the water dimer. They concluded that the interplay between BSSE and incomplete description of the electron cusp leads to unsystematic and nonmonotonic convergence of both the SCF and correlation energies for MP2 and CCSD (T) wave functions. In our case, the SCF part of the binding energies converge monotonically toward the basis set limit whereas the correlation part decreases upon going from aVDZ to aVTZ basis set before smoothly increasing toward the CBS limit. An extrapolation function like the one used in the 4-5 inverse polynomial schemes has the flexibility to fit nonmonotonic binding energies better than the conventional extrapolation function. Thus, we will use the 4-5 inverse polynomial scheme in all further basis set extrapolations.

4.2. Error Due to the RI Approximation. RI-MP2 with good auxiliary basis sets performs as well as conventional MP2 while requiring less CPU time, memory and disk space. For our calculations with more than 100 basis functions, the time spent in the MP2 module is reduced by at least a factor of 10 in the case of RI-MP2 compared to conventional MP2. These substantial computational savings come without sacrificing any significant accuracy. In fact, the difference between binding energies calculated using RI-MP2/aVDZ and MP2/aVDZ//RI-MP2/ aVDZ is less than $0.06 \mathrm{kcal} / \mathrm{mol}$ for $\left(\mathrm{H}_{2} \mathrm{O}\right)_{n=2-10}$. The effect of the RI approximation on the interaction energies of the S22 noncovalently bound molecules has also been shown to be negligible. $^{103}$

4.3. Convergence of Geometries. RI-MP2/aVTZ structures are very similar to RI-MP2/aVDZ optimized structures as tested for $\left(\mathrm{H}_{2} \mathrm{O}\right)_{n=1-6}$. Table $\mathrm{S} 1$ shows the difference between RIMP2/aVTZ and RI-MP2/aVDZ geometries and the subsequent differences in binding energy between RIMP/aVTZ//aVDZ and RI-MP2/aVTZ. The difference is small $(<0.2 \mathrm{kcal} / \mathrm{mol})$ except for those structures with hydrogen bond angles deviating substantially from 180 hydrogen bonds like the prism tetramer. The root-mean-square deviation ( $\mathrm{rmsd}$ ) of the coordinates of the RI-MP2/aVDZ optimized clusters relative to the RI-MP2/aVTZ ones is less than $0.1 \AA$ for all the clusters. Thus, we believe that the RI-MP2/aVDZ geometries are sufficiently converged.

4.4. Higher-Order Electron Correlation Correction. The importance of higher-order dynamical electron correlation 
Table 2. $\operatorname{CCSD}(\mathrm{T}) / \mathrm{CBS}^{a}$ Harmonic and Scaled Harmonic Binding Energies for $\left(\mathrm{H}_{2} \mathrm{O}\right)_{n=2-6}{ }^{b}$

\begin{tabular}{|c|c|c|c|c|c|c|c|}
\hline \multirow[b]{2}{*}{$\left(\mathrm{H}_{2} \mathrm{O}\right)_{n}{ }^{c}$} & \multirow[b]{2}{*}{$\Delta E_{\mathrm{e}}$} & \multicolumn{3}{|c|}{ harmonic } & \multicolumn{3}{|c|}{ scaled harmonic } \\
\hline & & $\Delta H(0)$ & $\Delta H^{0}(298)$ & $\Delta G^{0}(298)$ & $\Delta H(0)$ & $\Delta H^{\circ}(298)$ & $\Delta G^{0}(298)$ \\
\hline $2-\left(C_{s}\right)$ & -5.03 & -2.93 & -3.38 & 2.65 & -3.14 & -3.43 & 2.05 \\
\hline 3-UUD & -15.70 & -10.25 & -12.02 & 4.47 & -10.63 & -12.06 & 3.46 \\
\hline 3-UUU $\left(C_{3}\right)$ & -15.08 & -10.03 & -11.57 & 4.91 & -10.40 & -11.61 & 3.87 \\
\hline 4- $\left(S_{4}\right)$ & -27.43 & -19.21 & -21.92 & 4.56 & -19.74 & -21.96 & 3.11 \\
\hline 4- $\left(C_{i}\right)$ & -26.58 & -18.56 & -21.16 & 4.38 & -19.08 & -21.20 & 2.91 \\
\hline 4-PY & -23.88 & -16.04 & -18.41 & 6.05 & -16.56 & -18.45 & 4.54 \\
\hline 5-CYC & -36.01 & -25.63 & -28.83 & 5.06 & -26.29 & -28.88 & 3.10 \\
\hline 5-FR-B & -34.87 & -24.44 & -27.62 & 6.95 & -25.11 & -27.67 & 4.98 \\
\hline 5-CA-C & -34.69 & -24.03 & -27.35 & 7.99 & -24.70 & -27.38 & 6.04 \\
\hline 5-CA-A & -34.54 & -23.86 & -27.18 & 8.31 & -24.53 & -27.21 & 6.35 \\
\hline 5-CA-B & -33.82 & -23.16 & -26.44 & 8.73 & -23.83 & -26.48 & 6.77 \\
\hline 5-FR-C & -32.44 & -22.21 & -25.27 & 8.98 & -22.87 & -25.31 & 7.00 \\
\hline 5-FR-A & -33.13 & -22.57 & -25.81 & 8.95 & -23.23 & -25.85 & 6.99 \\
\hline 6-PR & -46.14 & -32.33 & -36.72 & 9.33 & -33.16 & -36.76 & 6.95 \\
\hline 6-CA & -45.93 & -32.32 & -36.66 & 9.13 & -33.14 & -36.69 & 6.74 \\
\hline 6-BK-1 & -45.51 & -32.30 & -36.39 & 7.94 & -33.11 & -36.44 & 5.52 \\
\hline 6-BK-2 & -45.14 & -31.93 & -36.03 & 8.02 & -32.74 & -36.08 & 5.61 \\
\hline 6-CC $\left(S_{6}\right)$ & -44.60 & -31.96 & -35.67 & 7.64 & -32.76 & -35.73 & 5.18 \\
\hline 6-BAG & -44.59 & -31.55 & -35.57 & 8.77 & -32.36 & -35.62 & 6.35 \\
\hline 6-CB-1 $\left(C_{2}\right)$ & -43.57 & -31.12 & -34.72 & 7.63 & -31.91 & -34.78 & 5.16 \\
\hline 6-CB-2 $\left(\mathrm{C}_{2}\right)$ & -43.51 & -31.24 & -34.74 & 7.43 & -32.03 & -34.81 & 4.95 \\
\hline
\end{tabular}

Table 3. $\operatorname{CCSD}(\mathrm{T}) / \mathrm{CBS}^{a}$ Harmonic and Scaled Harmonic Binding Energies for $\left(\mathrm{H}_{2} \mathrm{O}\right)_{n=7-10} b$

\begin{tabular}{|c|c|c|c|c|c|c|c|}
\hline \multirow[b]{2}{*}{$\left(\mathrm{H}_{2} \mathrm{O}\right)_{n}{ }^{c}$} & \multirow[b]{2}{*}{$\Delta E_{\mathrm{e}}$} & \multicolumn{3}{|c|}{ harmonic } & \multicolumn{3}{|c|}{ scaled harmonic } \\
\hline & & $\begin{array}{l}\Delta H \\
(0)\end{array}$ & $\begin{array}{l}\Delta \Delta H^{0} \\
(298)\end{array}$ & $\begin{array}{l}\Delta G^{0} \\
(298)\end{array}$ & $\begin{array}{l}\Delta H \\
(0)\end{array}$ & $\begin{array}{c}\Delta H^{0} \\
(298)\end{array}$ & $\begin{array}{c}\Delta G^{0} \\
(298)\end{array}$ \\
\hline 7-PR1 & -57.37 & -40.83 & -46.10 & 9.80 & -41.81 & -46.16 & 6.96 \\
\hline 7-PR2 & $-5 \% .10$ & -40.47 & -45.80 & 10.25 & -41.44 & -45.84 & 7.41 \\
\hline 7-PR3 & $-x$ & -4 & -45 & 9.92 & -41.53 & & 66 \\
\hline 7-CA1 & -55.6 & -35 & -44.68 & 10.12 & -40.68 & & 25 \\
\hline 7-CA2 & -54.8 & -3 & -43.94 & 10.33 & -40.02 & - & 7. \\
\hline 7-CH1 & -54.3 & -38.86 & -43.52 & 9.24 & -39.81 & -4 & 6. \\
\hline $7-\mathrm{CH} 2$ & -53.87 & -38.42 & -43.06 & 9.33 & -39.36 & -4 & 6.43 \\
\hline 7-BI1 & -53.40 & -37.88 & -42.49 & 9.89 & -38.83 & -4 & 6.98 \\
\hline 7-BI2 & -53.3 & -37.86 & -42.45 & 9.50 & -38 & -4 & 6. \\
\hline $7-\mathrm{CH}$ & -53.0 & -37.93 & -42.36 & 9.38 & -38.87 & -4 & 6.44 \\
\hline 7-HM & -52.3 & -37 & -41.57 & 10.09 & -38.20 & -4 & 7.13 \\
\hline $8-\left(D_{2 d}\right)$ & -72.55 & -52.06 & -58.91 & 10.12 & -53.21 & -58.98 & 6.90 \\
\hline $8-\left(S_{4}\right)$ & -72.55 & -52.09 & -58.95 & 9.61 & -53.24 & -59.02 & 6.40 \\
\hline 9-D2dDD & -81.70 & -59.09 & -66.48 & 10.55 & -60.38 & -66.55 & 6.84 \\
\hline 9-S4DA & -81.46 & -58.84 & -66.23 & 10.74 & -60.13 & -66.30 & 7.04 \\
\hline 10-PP1 & -92.89 & -67.35 & -75.73 & 11.93 & -68.78 & -75.80 & 7.78 \\
\hline 10-PP2 & -92.89 & -67.20 & -75.63 & 11.98 & & -75.72 & 7.83 \\
\hline \multicolumn{8}{|c|}{$\begin{array}{l}\text { - Calculated as } E_{C B S}^{C C S D(T)}=E_{C B S}^{R I-M P 2}+\delta_{M P 2}^{C C S D(T)} \text {. See text for details } \\
\text { - All thermodynamic corrections calculated using RI-MP2/aVDZ geome } \\
\text { ries and vibrational frequencies. All energies are in kcal } / \mathrm{mol}^{c}{ }^{c}-\text { High poin } \\
\text { rroup symmetries shown in paranthesis. Global minima shown in bold. }\end{array}$} \\
\hline
\end{tabular}

can be assessed by looking at the $\operatorname{CCSD}(\mathrm{T})$ correction to the MP2 binding energy $\left(\delta_{\mathrm{MP} 2}^{\mathrm{CCSD}(\mathrm{T})}\right)$ as defined by eq 5 . The $\operatorname{CCSD}(\mathrm{T})$ correction to the MP2 binding energies is small relative to the absolute binding energy, but it affects the

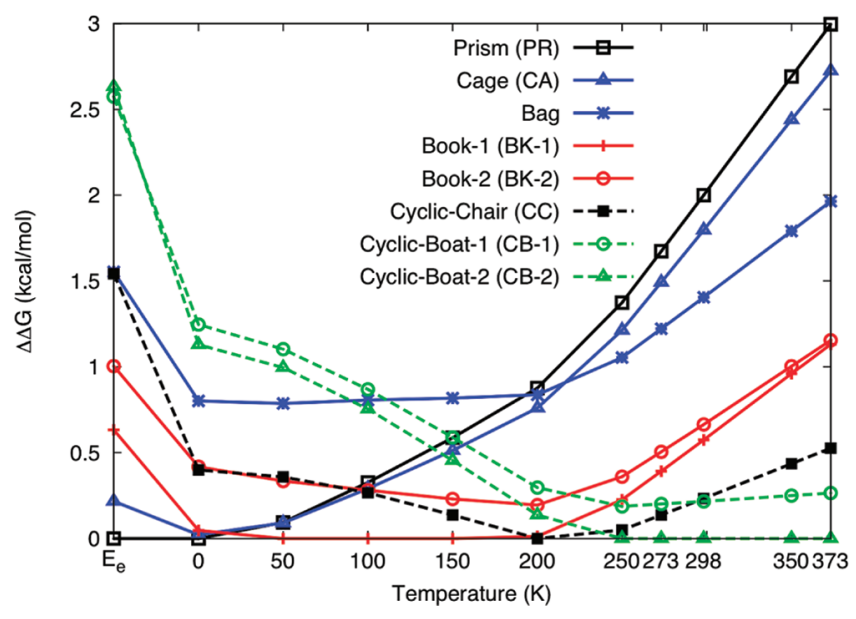

Figure 8. Scaled harmonic CCSD $(\mathrm{T}) / \mathrm{CBS}$ relative Gibbs free energy of eight conformers of $\left(\mathrm{H}_{2} \mathrm{O}\right)_{6}$ as a function of temperature.

relative energies of isomers substantially. A notable case is the water hexamer for which the $\operatorname{CCSD}(\mathrm{T})$ correction increases the binding energy of the prism by $0.14 \mathrm{kcal} / \mathrm{mol}$ while decreasing that of the cage, book and cyclic structures by $0.03,0.26$, and $0.47 \mathrm{kcal} /$ mol, respectively. Cyclic and planar structures are typically destabilized while more 3-D structures are significantly favored. The nondynamical correlation can be evaluated by calculating $T_{1}$ diagnostic values for CCSD wave functions. ${ }^{123}$ As a general rule of thumb, $T_{1}$ diagnostic values smaller than 0.02 indicate that a single reference wave function is appropriate and that the 
multireference character in the system should be negligible. The $T_{1}$ diagnostic values for $\left(\mathrm{H}_{2} \mathrm{O}\right)_{n=1-10}$ are all less than the 0.02 threshold above which multireference treatment becomes important. It is interesting that the $T_{1}$ diagnostic for the larger water clusters hardly differs from that of the isolated water monomer

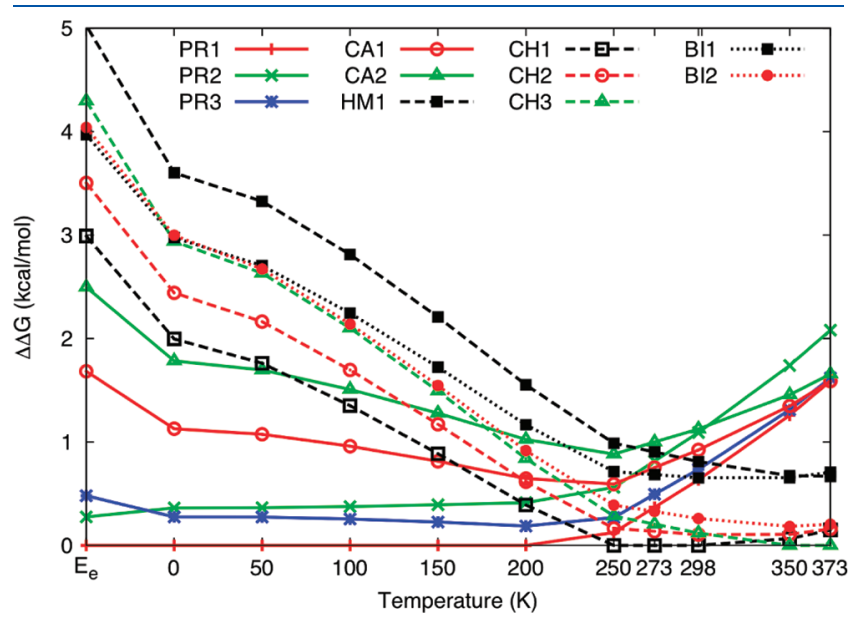

Figure 9. Scaled harmonic $\operatorname{CCSD}(\mathrm{T}) / \mathrm{CBS}$ relative Gibbs free energy of eight isomers of $\left(\mathrm{H}_{2} \mathrm{O}\right)_{7}$ as a function of temperature at $1 \mathrm{~atm}$ pressure. despite all of the hydrogen bonding and relaxation of the monomer geometries in the clusters. Xantheas at al. ${ }^{91,124}$ and Klopper et al. ${ }^{125}$ estimated the effect of higher order electron correlation as a $\operatorname{CCSD}(\mathrm{T})$ correction to the MP2/CBS binding energies. They concluded that this correction is very small and its effects are often canceled out by core-valence correlation corrections that are not included in their frozen-core MP2 calculations. For the case of $\left(\mathrm{H}_{2} \mathrm{O}\right)_{8}$, they report the $\mathrm{CCSD}(\mathrm{T})$ correction to be less than $0.1 \mathrm{kcal} / \mathrm{mol} .^{117}$ Although the $\operatorname{CCSD}(\mathrm{T})$ correction to the MP2 binding energy reported in other works ${ }^{91,110,117}$ always has a stabilizing effect, our results indicate that it in fact often decreases the MP2 binding energies.

4.5. Correcting for Vibrational Anharmonicity. We evaluated (a) the ability of our frequency scaling factors to map harmonic values onto anharmonic ones and (b) the magnitude of the anharmonic correction to the ZPVE, $\Delta H_{\text {vib, }}$ and $S_{\text {vib. The }}$ scaled harmonic ZPVE is calculated by multiplying the harmonic ZPVE by 0.976 (see ref 107), whereas the anharmonic values correspond to an estimate of the true ZPVE (see eq 7 in ref 107). For $\Delta H_{\text {vib }}$ and $S_{\text {vib }}$, the harmonic and anharmonic values are computed using eqs 16 and 17 in ref 107 . The frequency scaling factors used were $\lambda_{\mathrm{H}}=0.868$ and $\lambda_{\mathrm{S}}=0.844$ for $\Delta H_{\text {vib }}$ and $S_{\text {vib }}$ at $298.15 \mathrm{~K}$. Figure $7 \mathrm{a}-\mathrm{c}$ displays a comparison of ZPVE, $\Delta H_{\mathrm{vib}^{-}}$ $(298.15 \mathrm{~K})$, and $S_{\mathrm{vib}}(298.15 \mathrm{~K})$ for 11 water clusters. It is evident that application of our scaling factors works remarkably well in mapping the harmonic values to their anharmonic analogs. The

Table 4. $\operatorname{CCSD}(\mathrm{T}) / \mathrm{CBS}^{a}$ Boltzmann Averaged Scaled Harmonic Binding Free Energy of Water Clusters at Various Temperatures for Reactions of Type $n\left(\mathrm{H}_{2} \mathrm{O}\right) \rightarrow\left(\mathrm{H}_{2} \mathrm{O}\right)_{n}{ }^{b}$

\begin{tabular}{cccccccccccc}
\multicolumn{10}{c}{$\Delta G_{n}(T)-n^{*} \Delta G_{1}(T)$} \\
\cline { 2 - 12 }$\left(\mathrm{H}_{2} \mathrm{O}\right)_{n}$ & $T=0 \mathrm{~K}$ & 50 & 100 & 150 & 200 & 250 & 273.15 & 298.15 & 350 & 373.15 \\
2 & -3.14 & -2.64 & -1.73 & -0.76 & 0.20 & 1.15 & 1.59 & 2.05 & 3.01 & 3.41 \\
3 & -10.63 & -9.22 & -6.82 & -4.22 & -1.58 & 1.07 & 2.29 & 3.60 & 6.31 & 7.48 \\
4 & -19.74 & -17.32 & -13.46 & -9.32 & -5.13 & -0.95 & 0.98 & 3.05 & 7.35 & 9.21 \\
5 & -26.29 & -23.08 & -18.16 & -12.87 & -7.46 & -2.01 & 0.52 & 3.22 & 8.87 & 11.32 \\
6 & -33.16 & -28.76 & -22.19 & -15.22 & -8.22 & -1.30 & 1.88 & 5.26 & 12.28 & 15.32 \\
7 & -41.81 & -36.32 & -28.12 & -19.3 & -10.27 & -1.48 & 2.48 & 6.67 & 15.31 & 19.04 \\
8 & -53.24 & -46.55 & -36.64 & -25.98 & -15.06 & -4.05 & 1.07 & 6.55 & 17.99 & 22.97 \\
9 & -60.38 & -52.76 & -41.56 & -29.56 & -17.3 & -4.95 & 0.78 & 6.92 & 19.72 & 25.30 \\
10 & -68.78 & -60.06 & -47.33 & -33.71 & -19.76 & -5.71 & 0.81 & 7.80 & 22.38 & 28.73
\end{tabular}

${ }^{a}$ Calculated as $E_{\mathrm{CBS}}^{\mathrm{CCSD}(\mathrm{T})}=E_{\mathrm{CBS}}^{\mathrm{RI}-\mathrm{MP2}}+\delta_{\mathrm{MP2}}^{\mathrm{CCSD}(\mathrm{T})}$. See text for details. ${ }^{b}$ The pressure is $1 \mathrm{~atm}$. All energies are in $\mathrm{kcal} / \mathrm{mol}$.

Table 5. $\operatorname{CCSD}(\mathrm{T}) / \mathrm{CBS}^{a}$ Boltzmann Averaged Scaled Harmonic Binding Free Energy of Water Clusters at Various Temperatures for Reactions of Type $\left(\mathrm{H}_{2} \mathrm{O}\right)+\left(\mathrm{H}_{2} \mathrm{O}\right)_{n-1} \stackrel{\rightarrow}{\rightarrow}\left(\mathrm{H}_{2} \mathrm{O}\right)_{n}{ }^{b}$

\begin{tabular}{|c|c|c|c|c|c|c|c|c|c|c|}
\hline \multirow[b]{2}{*}{$\left(\mathrm{H}_{2} \mathrm{O}\right)_{n}$} & \multicolumn{10}{|c|}{$\Delta G_{n}(T)-\left\{\Delta G_{1}(T)+\Delta G_{n-1}(T)\right\}$} \\
\hline & $T=0 \mathrm{~K}$ & 50 & 100 & 150 & 200 & 250 & 273.15 & 298.15 & 350 & 373.15 \\
\hline 2 & -3.14 & -2.64 & -1.73 & -0.76 & 0.20 & 1.15 & 1.59 & 2.05 & 3.01 & 3.41 \\
\hline 3 & -7.49 & -6.58 & -5.09 & -3.46 & -1.78 & -0.08 & 0.70 & 1.55 & 3.31 & 4.07 \\
\hline 4 & -9.11 & -8.09 & -6.64 & -5.09 & -3.55 & -2.02 & -1.31 & -0.55 & 1.03 & 1.72 \\
\hline 5 & -6.55 & -5.76 & -4.70 & -3.56 & -2.33 & -1.06 & -0.46 & 0.18 & 1.52 & 2.12 \\
\hline 6 & -6.87 & -5.68 & -4.03 & -2.35 & -0.76 & 0.71 & 1.36 & 2.04 & 3.41 & 4.00 \\
\hline 7 & -8.65 & -7.56 & -5.92 & -4.08 & -2.05 & -0.18 & 0.60 & 1.41 & 3.03 & 3.72 \\
\hline 8 & -11.44 & -10.23 & -8.52 & -6.68 & -4.79 & -2.57 & -1.41 & -0.12 & 2.68 & 3.93 \\
\hline 9 & -7.13 & -6.21 & -4.92 & -3.58 & -2.24 & -0.90 & -0.29 & 0.37 & 1.73 & 2.32 \\
\hline 10 & -8.41 & -7.30 & -5.78 & -4.14 & -2.46 & -0.76 & 0.03 & 0.88 & 2.66 & 3.44 \\
\hline
\end{tabular}


apparent gap between the harmonic and anharmonic values for ZPVE, $\Delta H_{\text {vib }}$, and $S_{\text {vib }}$ in Figure 7 is indicative of the importance of anharmonicity. The anharmonic correction, which we define as the difference between the harmonic and anharmonic values as a percentage of the anharmonic value, is $1.8-2.7 \%$ for the ZPVE, $8.7-13.4 \%$ for the $\Delta H_{\mathrm{vib}}$, and $10.7-17.2 \%$ for the $S_{\mathrm{vib}}$. Given such large anharmonic corrections, it is important to account for them. More importantly, when scaling factors are used to correct for anharmonicity, it is essential to use the most appropriate scaling factors. Applying scaling factors intended for covalently bonded systems to hydrogen-bonded clusters could lead to large errors.

4.6. Benchmark $\operatorname{CCSD}(\mathrm{T})$ Binding Energies. The binding energies of small water clusters have been studied exhaustively in the literature. The global minumum structures from this anharmonicity corrected CCSD $(\mathrm{T}) / \mathrm{CBS}$ study agree well with our previous work using an MP2/CBS estimate. ${ }^{\text {Po }}$ As will be shown below, anharmonic corrections rarely change the energetic ordering of different isomers; rather, they lower the free energy of all the isomers. For the water dimer, the $\mathrm{C}_{\mathrm{s}}$ isomer has long been known ${ }^{126,127}$ to be the global minimum structure. Our RI$\mathrm{MP} 2 / \mathrm{CBS}$ electronic binding energy $\left(\Delta E_{\mathrm{e}}\right.$ or $\left.D_{\mathrm{e}}\right)$ of $-5.00 \mathrm{kcal} / \mathrm{mol}$ compares well with MP2/CBS prediction of Xantheas et al. ${ }^{91}$ $(-4.97 \mathrm{kcal} / \mathrm{mol})$ and Klopper et al. ${ }^{128}(-5.00 \mathrm{kcal} / \mathrm{mol})$. Our best $\operatorname{CCSD}(\mathrm{T}) / \mathrm{CBS}$ value $(-5.03 \mathrm{kcal} / \mathrm{mol})$ agrees with the corresponding $\operatorname{CCSD}(\mathrm{T})-\mathrm{F} 12 \mathrm{a} / \mathrm{VQZ}-\mathrm{F} 12$ binding energy $(-4.99 \mathrm{kcal} / \mathrm{mol})$ of Lane et al., ${ }^{129} \operatorname{CCSD}(\mathrm{T}) / \mathrm{CBS}$ analog $(-5.02 \pm 0.05 \mathrm{kca} / \mathrm{mol})$ of Klopper et al. ${ }^{128}$ and $-5.02 \pm$ $0.07 \mathrm{kca} / \mathrm{mol}$ of Tschumper et al. ${ }^{127}$ Likewise, our ZPVE corrected $\mathrm{CCSD}(\mathrm{T}) / \mathrm{CBS}$ binding energy, referred to as $\triangle E(0)$, $\Delta H(0), \Delta G(0)$, or $D_{0}$, of $-2.93 \mathrm{kcal} / \mathrm{mol}$ compares favorably with Lane et al.'s ${ }^{129} \operatorname{CCSD}(\mathrm{T})-\mathrm{F} 12 \mathrm{a} / \mathrm{VQZ}-\mathrm{F} 12$ value of -2.91 $\mathrm{kcal} / \mathrm{mol}$ but differs rather substantially from Klopper et al.'s ${ }^{128}$ estimate of $-3.30 \pm 0.10 \mathrm{kcal} / \mathrm{mol}$. The best experimental estimate for $D_{0}$ has been determined to be $-3.15 \pm 0.03 \mathrm{kcal} /$ mol by Rocher-Casterline et al. ${ }^{130}$ using velocity map imaging. This value is in great agreement with our scaled harmonic value of $-3.14 \mathrm{kcal} / \mathrm{mol}$ and Shank et al's ${ }^{131}$ suggested benchmark value of $-3.15 \pm 0.01 \mathrm{kcal} / \mathrm{mol}$. This is an early indication that accounting for anharmonic effects is critical to achieve benchmark quality binding energies of water clusters.

The harmonic CCSD $(\mathrm{T}) / \mathrm{CBS} \Delta G(298.15 \mathrm{~K})$ value is 2.65 $\mathrm{kcal} / \mathrm{mol}$ is nearly identical to Lane et al.'s ${ }^{129} \operatorname{CCSD}(\mathrm{T})-\mathrm{F} 12 \mathrm{a} /$ VQZ-F12 estimate of $2.61 \mathrm{kcal} / \mathrm{mol}$, but correcting for anharmonicity lowers it to $2.05 \mathrm{kcal} / \mathrm{mol}$. A large part of that correction is a result of the large anharmonicity of its low frequency intermolecular modes, which contribute the most to its entropy. The binding enthalpy and entropy of the water dimer has been determined experimentally from thermal conductivity measurements at four temperatures between 358 and $386 \mathrm{~K}$ and at pressures between 100 and 1000 Torr. ${ }^{132}$ The reported $\Delta G(373 \mathrm{~K})$ value of $3.34 \pm 1.0 \mathrm{kcal} / \mathrm{mol}$ is considered a lower limit ${ }^{133}$ to the true value and our scaled harmonic $\Delta G(373 \mathrm{~K})$ of $3.41 \mathrm{kcal} / \mathrm{mol}$ lies slightly above the experimental value. Our scaled harmonic $\Delta H(373 \mathrm{~K})$ of $-3.22 \mathrm{kcal} / \mathrm{mol}$ also agrees with the experimental dimerization enthalpy of $-3.59 \pm 0.5 \mathrm{kcal} / \mathrm{mol}$.

For the water trimer the $\operatorname{UUD}\left(C_{1}\right)$ and $\operatorname{UUU}\left(C_{3}\right)$ isomers are the two most important structures, and $\operatorname{UUD}\left(C_{1}\right)$ is more stable over our temperature range $(T<373 \mathrm{~K})$. Our RI-MP2/CBS binding energy of $-15.72 \mathrm{kcal} / \mathrm{mol}$ for the UUD isomer is in close agreement with Xantheas ${ }^{91}$ estimate of $-15.82 \mathrm{kcal} / \mathrm{mol}$. Klopper et al. ${ }^{125}$ have studied many stationary points on the water trimer potential energy surface using the explicitly correlated
MP2-R12 method. They also find the UUD to be the global minimum, but note that UUU local minimum is very important since the torsional barrier for the UUD to UUU conversion is only $10 \mathrm{~cm}^{-1}$. The MP2-R12/PW-dz binding energies they report for the UUD $(-16.32 \mathrm{kcal} / \mathrm{mol})$ and UUU $(-15.53 \mathrm{kcal} / \mathrm{mol})$ isomers are smaller than ours.

The water tetramer has three prominent isomers and the $S_{4}$ structure is more stable at lower temperatures, but the $C_{i}$ isomer is favored at higher temperatures because it has a lower rotational symmetry and, hence, a higher rotational entropy. The water pentamer is the largest cluster size for which planar structures are overwhelmingly favored over more three-dimensional conformations. Of the seven isomers of the water pentamer, the CYC ring structure is the most stable at all temperatures and the CA (cage) and FR (fused-ring) isomers consistently lie at least $1 \mathrm{kcal} / \mathrm{mol}$ higher in energy. It is clear that water trimers, tetramer, and pentamers overwhelmingly prefer forming planar cyclic rings at ambient temperatures.

The most interesting water clusters are the hexamer and heptamer because they define a size region where planar, quasiplanar and three-dimensional conformations are competitive. The conformational free energy as a function of temperature for the water hexamers and heptamers is displayed in Figures 8 and 9. For the hexamer, the PR (prism) is the most stable isomer by electronic binding energy $\left(\Delta E_{\mathrm{e}}\right)$, followed by the CA (cage) isomer, which lies just $0.21 \mathrm{kcal} / \mathrm{mol}$ higher, whereas all other isomers are less stable by at least $0.50 \mathrm{kcal} / \mathrm{mol}$. After the inclusion of zero-point vibrational energy corrections, the PR isomer remains the global minimum while the CA and BK-1 (book-1) isomers are virtually degenerate, lying just 0.02 and $0.05 \mathrm{kcal} / \mathrm{mol}$ higher, respectively. Our results are largely consistent with the most recent benchmark work on the water hexamer. ${ }^{110}$ At higher temperatures, the quasi-planar BK-1 is the most stable isomer for $T<200 \mathrm{~K}$ and the planar cyclic boat (CB) and cyclic chair (CC) isomers become more favorable for $T>200 \mathrm{~K}$. Overall, the isomers with the most hydrogen bonds, namely $\operatorname{PR}(9)$ and $\mathrm{CA}(8)$ are favored at low temperatures while the $\mathrm{BK}(7)$ species has the lowest free energy at intermediate temperatures and the $\mathrm{CC}(6)$ and $\mathrm{CB}(6)$ isomers are the most stable at atmospherically relevant temperatures. Considering how close the energies of these isomers are, one would likely observe an ensemble of these isomers at low temperatures depending on the exact experimental condition. ${ }^{134-136}$

Just like the hexamer, the heptamer has planar, quasi-planar and nonplanar isomers with varying stability depending on a given temperature range. The prism (PR1, PR2, PR3) isomers are the most stable heptamers up to $T=200 \mathrm{~K}$ and the quasiplanar isomers become more favorable at higher temperatures. Once again, it is important to note that anharmonic corrections, as included by frequency scaling, do not change the energetic ordering of the isomers substantially, but they do lower the binding free energies of all isomers. For $\left(\mathrm{H}_{2} \mathrm{O}\right)_{8}$, the $D_{2 d}$ and $S_{4}$ isomers have been known to be far more stable than other noncubic structures. Computational work by Day et al. ${ }^{137}$ showed that the cubic isomers are favorable at $T<298 \mathrm{~K}$, whereas Xantheas et al. ${ }^{117}$ calculated benchmark binding energies for the $D_{2 d}$ and $S_{4}$ isomers. The two isomers have also been observed experimentally. ${ }^{138,139}$ Our CCSD $(\mathrm{T}) / \mathrm{CBS}$ study also finds the two to be virtually degenerate. The main difference arises from the higher rotational symmetry $(\sigma)$ of the $D_{2 d}(\sigma=4)$ isomer compared to $S_{4}(\sigma=2)$. Since $S_{4}$ has a higher rotational entropy, it is favored slightly at higher temperatures. Our previous study ${ }^{108}$ 
and others ${ }^{140}$ have identified eight isomers of the water nonamer that were within $2 \mathrm{kcal} / \mathrm{mol}$ of the $\Delta G(298 \mathrm{~K})$ minimum structure. They were all stacks of a planar cyclic pentamer and tetramer. Of these, we selected the two most stable ones for this study. The $\mathrm{D} 2 \mathrm{dDD}$ isomer is the most stable at all temperatures and the S4DA isomer lies within $0.3 \mathrm{kcal} / \mathrm{mol}$ of the minimum at most temperatures. Lastly, we had identified 30 low energy isomers of the water decamer that were within $2 \mathrm{kcal} / \mathrm{mol}$ of the $\Delta G(298 \mathrm{~K})$ minimum structure. ${ }^{108}$ The stacked pentagonal prism (PP) structures were found to be the most stable up to $T=320 \mathrm{~K}$. We have looked at the two lowest energy PP structures (PP1 and PP2), which differ only in the orientation of the homodromic hydrogen bonds in each pentagonal face. The two remain essentially isoenergetic at all temperatures.

4.7. Thermodynamics of Water Cluster Growth. To understand the formation of water clusters, we took a Boltzmann average of the free energies of each isomer of size $n$ and calculated $\Delta G_{\mathrm{T}}(\mathrm{n})$ using the formalism shown in eqs 8 and 9. These values are tabulated in Table 4 for $n\left(\mathrm{H}_{2} \mathrm{O}\right) \rightarrow\left(\mathrm{H}_{2} \mathrm{O}\right)_{n}$ and Table 5 for $\left(\mathrm{H}_{2} \mathrm{O}\right)+\left(\mathrm{H}_{2} \mathrm{O}\right)_{n-1} \rightarrow\left(\mathrm{H}_{2} \mathrm{O}\right)_{n}$. The data is also displayed graphically in Figure 10. The picture that emerges from evaluating the free energies is that the formation of small water clusters is favorable up to $T=200 \mathrm{~K}$. In general, $\left(\mathrm{H}_{2} \mathrm{O}\right)_{4}$ and $\left(\mathrm{H}_{2} \mathrm{O}\right)_{8}$ are more stable than other cluster sizes. That picture is consistent with the findings from our previous work. ${ }^{108}$ The inclusion of anharmonic corrections here lowers the Boltzmann averaged $\Delta G_{\mathrm{T}}(n)$ by as much as $4 \mathrm{kcal} / \mathrm{mol}$ for $n\left(\mathrm{H}_{2} \mathrm{O}\right) \rightarrow\left(\mathrm{H}_{2} \mathrm{O}\right)_{n}$ and $0.6 \mathrm{kcal} / \mathrm{mol}$ for $\left(\mathrm{H}_{2} \mathrm{O}\right)+\left(\mathrm{H}_{2} \mathrm{O}\right)_{n-1} \rightarrow\left(\mathrm{H}_{2} \mathrm{O}\right)_{n}$.

The role of water clusters in the atmosphere has been debated in the literature. ${ }^{133,141-144}$ In particular, the abundance of water clusters and their absorption of solar radiation remains an active area. $^{145-147}$ In the troposphere, which extends up to $12 \mathrm{~km}$ above the earth's surface, the temperature ranges from $216.65 \mathrm{~K}$ at the upper end to about $300 \mathrm{~K}$ at ground level and atmospheric pressure varies from 0.2 to 1 atm over the same altitude profile. ${ }^{148}$ Although the formation of water clusters is generally more favorable at lower temperatures (i.e., higher altitudes), the partial pressure of water monomers is highest at lower altitudes. So, the interplay between temperature and atmospheric pressure will determine the abundance of water clusters.

At $298 \mathrm{~K}$, the concentration of water monomers at saturation ( $100 \%$ relative humidity) is about $9 \times 10^{17}$ particles $/ \mathrm{cm}^{-3}$. Given our CCSD(T)/CBS dimerization Gibbs free energy of $2.05 \mathrm{kcal} / \mathrm{mol}$ at $298 \mathrm{~K}$, we calculate the equilibrium constant to be $0.031 \mathrm{~atm}^{-1}$. Thus, the concentration of the water dimer should be about $7 \times 10^{14}$ particles $/ \mathrm{cm}^{-3}$ which is consistent with earlier predictions by Dunn et al. ${ }^{143}$ On the basis of their free energies of formation, larger water oligamers should be present in the atmosphere with abundances of $10^{12}$ particles $/ \mathrm{cm}^{-3}$ and less. The concentration of these water clusters remains much larger than those of common aerosols in the atmosphere. Therefore, the role of water clusters in gas phase atmospheric chemistry is predicted to be significant. Clusters of waters results in solar absorption over a broader range to infrared wavelengths, therefore the contribution of water clusters to global warming should be important. ${ }^{136}$

\section{CONCLUSION}

We combined molecular dynamics sampling with quantum mechanical minimizations to determine the low energy isomers of small water clusters of sizes $2-10$. We presented RI-MP2/CBS binding and conformational energies and included corrections
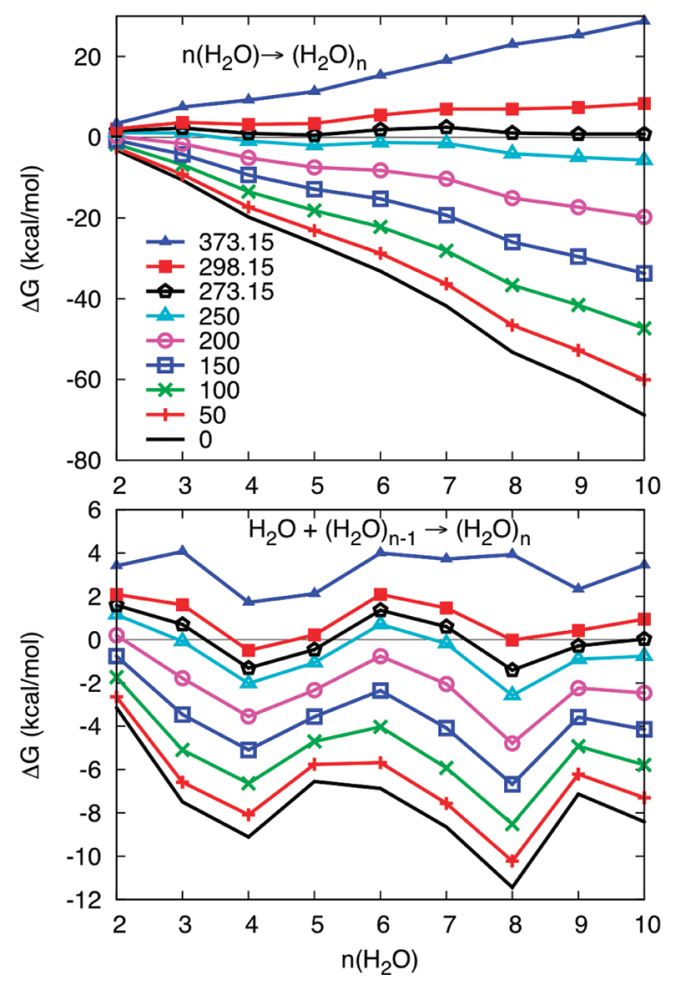

Figure 10. Scaled harmonic CCSD(T)/CBS total (top) and stepwise (bottom) Gibbs free energy changes due to the formation of small water clusters at various temperatures and $1 \mathrm{~atm}$ pressure. $\Delta G(T)$ values are Boltzmann averaged over the low energy structures of each cluster.

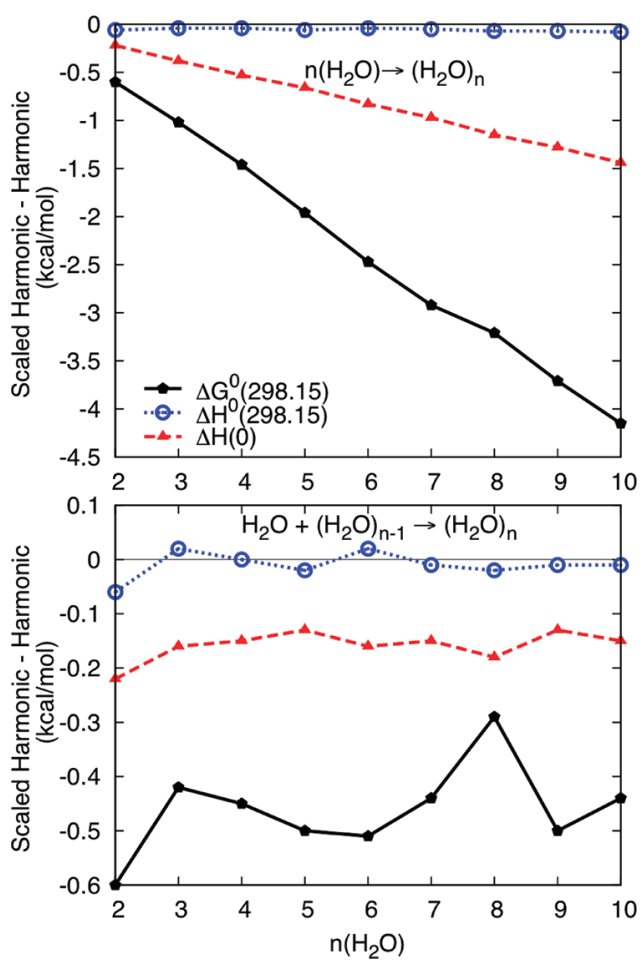

Figure 11. Anharmonic effects on the growth of water clusters. The top graph represents the total association energies while the bottom one corresponds to the stepwise addition. All energies are Boltzmann averaged over the low energy structures of each cluster. 
for higher-order electron correlations using $\operatorname{CCSD}(\mathrm{T})$ and anharmonicity using frequency scaling factors designed specifically for water clusters. The $\operatorname{CCSD}(\mathrm{T})$ correction to the MP2 binding energy was small but important in differentiating low energy isomers. Anharmonic effects were shown to lower the free energy of formation substantially even though they did not change the energetic ordering of different isomers. Overall, the free energy for the growth of water clusters is consistently negative only for $T<200 \mathrm{~K}$, suggesting that the formation of small water clusters (bigger than a pentamer) at ambient temperatures is unfavorable at low altitudes but increases at higher altitudes. Neverthless, the abundance of small water clusters in the troposphere is significant enough to impact many (a) gas phase reactions like the formation of aerosols and (b) global radiative forcing via absorption of solar radiation. This finding confirms earlier work reported using model chemistry methods. $^{143}$

\section{ASSOCIATED CONTENT}

S Supporting Information. All of the RI-MP2/aVDZ optimized geometries, a comparison of RI-MP2/aVTZ and RI$\mathrm{MP} 2 / \mathrm{aVDZ}$ geometries and binding energies, the error due to RI approximation, and frequency scaling factors for the ZPVE, $\Delta H_{\mathrm{vib}}(T)$, and $S_{\mathrm{vib}}(T)$. This material is available free of charge via the Internet at http://pubs.acs.org.

\section{AUTHOR INFORMATION}

\section{Corresponding Author}

*E-mail: george.shields@bucknell.edu.

\section{ACKNOWLEDGMENT}

Acknowledgment is made to the NSF and Bucknell University for their support of this work. This project was supported in part by NSF grant CHE-0848827, and by NSF grants CHE-0116435, CHE-0521063, and CHE-0849677 as part of the MERCURY high-performance computer consortium (http://www.mercuryconsortium.org).

\section{REFERENCES}

(1) Ludwig, R. Angew. Chem., Int. Ed. 2001, 40, 1808.

(2) Woutersen, S.; Emmerichs, U.; Bakker, H. J. Science 1997, 278, 658.

(3) Keutsch, F.; Saykally, R. J. Proc. Natl. Acad. Sci. U.S.A. 2001, 98, 10533.

(4) Kropman, M. F.; Bakker, H. J. Science 2001, 291, 2118.

(5) Ruan, C.-Y.; Lobastov, V. A.; Vigliotti, F.; Chen, S.; Zewail, A. H. Science 2004, 304, 80.

(6) Myneni, S.; Luo, Y.; Näslund, L. A.; Cavalleri, M.; Ojamäe, L.; Ogasawara, H.; Pelmenschikov, A.; Wernet, P.; Vaterlein, P.; Heske, C.; Hussain, Z.; Pettersson, L. G. M.; Nilsson, A. J. Phys.: Condens. Matter 2002, 14, L213.

(7) Bakker, H. J.; Nienhuys, H.-K. Science 2002, 297, 587.

(8) Wernet, P.; Nordlund, D.; Bergmann, U.; Cavalleri, M.; Odelius, M.; Ogasawara, H.; Näslund, L. A.; Hirsch, T. K.; Ojamäe, L.; Glatzel, P.; Pettersson, L. G. M.; Nilsson, A. Science 2004, 304, 995.

(9) Brubach, J. B.; Mermet, A.; Filabozzi, A.; Gerschel, A.; Roy, P. J. Chem. Phys. 2005, 122, 184509.

(10) Näslund, L. A.; Lüning, J.; Ufuktepe, Y.; Ogasawara, H.; Wernet, P.; Bergmann, U.; Pettersson, L. G. M.; Nilsson, A. J. Phys. Chem. B 2005, 109, 13835.
(11) Ohrwall, G.; Fink, R.; Tchaplyguine, M.; Ojamae, L.; Lundwall, M.; Marinho, R.; Naves De Brito, A.; Sorensen, S.; Gisselbrecht, M.; Feifel, R.; Rander, T.; Lindblad, A.; Schulz, J.; Saethre, L. J.; Martensson, N.; Svensson, S.; Bjorneholm, O. J. Chem. Phys. 2005, 123, 054310.

(12) Naslund, L. A.; Edwards, D. C.; Wernet, P.; Bergmann, U.; Ogasawara, H.; Pettersson, L. G. M.; Myneni, S.; Nilsson, A. J. Phys. Chem. A 2005, 109, 5995.

(13) Hakala, M.; Nygard, K.; Manninen, S.; Pettersson, L. G. M.; Hamalainen, K. Phys. Rev. B 2006, 73, 035432.

(14) Alphonse, N. K.; Dillon, S. R.; Dougherty, R. C.; Galligan, D. K.; Howard, L. N. J. Phys. Chem. A 2006, 110, 7577.

(15) Bergmann, U.; Di Cicco, A.; Wernet, P.; Principi, E.; Glatzel, P.; Nilsson, A. J. Chem. Phys. 2007, 127, 174504.

(16) Winter, B.; Hergenhahn, U.; Faubel, M.; Bjorneholm, O.; Hertel, I. V. J. Chem. Phys. 2007, 127, 124504.

(17) Pastorczak, M.; Kozanecki, M.; Ulanski, J. J. Phys. Chem. A 2008, 112, 10705.

(18) Reategui, E.; Aksan, A. J. Phys. Chem. B 2009, 113, 13048.

(19) Abu-Samha, M.; Borve, K. J.; Winkler, M.; Harnes, J.; Saethre, L. J.; Lindblad, A.; Bergersen, H.; Ohrwall, G.; Bjorneholm, O.; Svensson, S. J. Phys. B: At., Mol. Opt. Phys. 2009, 42, 055201.

(20) Pokapanich, W.; Bergersen, H.; Bradeanu, I. L.; Marinho, R. R. T.; Lindblad, A.; Legendre, S.; Rosso, A.; Svensson, S.; Bjorneholm, O.; Tchaplyguine, M.; Ohrwall, G.; Kryzhevoi, N. V.; Cederbaum, L. S. J. Am. Chem. Soc. 2009, 131, 7264.

(21) Huse, N.; Wen, H. D.; Nordlund, D.; Szilagyi, E.; Daranciang, D.; Miller, T. A.; Nilsson, A.; Schoenlein, R. W.; Lindenberg, A. M. Phys. Chem. Chem. Phys. 2009, 11, 3951.

(22) Odelius, M. J. Phys. Chem. A 2009, 113, 8176.

(23) Wen, H. D.; Huse, N.; Schoenlein, R. W.; Lindenberg, A. M. J. Chem. Phys. 2009, 131, 234505.

(24) Sekine, Y.; Ikeda-Fukazawa, T. J. Phys. Chem. B 2010, 114, 3419.

(25) Sun, Q. J. Chem. Phys. 2010, 132, 054507.

(26) Benson, S. W.; Siebert, E. D. J. Am. Chem. Soc. 1992, 114, 4269.

(27) Silvestrelli, P. L.; Parrinello, M. J. Chem. Phys. 1999, 111, 3572.

(28) Geissler, P. L.; Dellago, C.; Chandler, D.; Hutter, J.; Parrinello, M. Science 2001, 291, 2121.

(29) Izvekov, S.; Voth, G. A. J. Chem. Phys. 2002, 116, 10372.

(30) Chen, B.; Ivanov, I.; Klein, M. L.; Parrinello, M. Phys. Rev. Lett. 2003, 91, 215503/1.

(31) Asthagiri, D.; Pratt, L. R.; Kress, J. D. Phys. Rev. E: Stat., Nonlinear, Soft Matter Phys. 2003, 68, 041505/1.

(32) Grossman, J. C.; Schwegler, E.; Draeger, E. W.; Gygi, F.; Galli, G. J. Chem. Phys. 2004, 120, 300.

(33) Allesch, M.; Schwegler, E.; Gygi, F.; Galli, G. J. Chem. Phys. 2004, 120, 5192.

(34) de la Pena, L. H.; Razul, M. S. G.; Kusalik, P. G. J. Chem. Phys. 2005, 123, 7236.

(35) Buch, V. J. Phys. Chem. B 2005, 109, 17771.

(36) Soper, A. K. J. Phys.: Condens. Matter 2005, 17, S3273.

(37) Lindenberg, A. M.; Acremann, Y.; Lowney, D. P.; Heimann, P. A.; Allison, T. K.; Matthews, T.; Falcone, R. W. J. Chem. Phys. 2005, 122, 204507.

(38) Prendergast, D.; Grossman, J. C.; Galli, G. J. Chem. Phys. 2005, $123,014501$.

(39) do Couto, P. C.; Estacio, S. G.; Cabral, B. J. C. J. Chem. Phys. 2005, 123, 204507.

(40) Jansen, T. L.; Hayashi, T.; Zhuang, W.; Mukamel, S. J. Chem. Phys. 2005, 123, 054510.

(41) Todorova, T.; Seitsonen, A. P.; Hutter, J.; Kuo, I. F. W.; Mundy, C. J. J. Phys. Chem. B 2006, 110, 3685.

(42) Fanourgakis, G. S.; Xantheas, S. S. J. Phys. Chem. A 2006, 110,4100 .

(43) Odelius, M.; Cavalleri, M.; Nilsson, A.; Pettersson, L. G. M. Phys. Rev. B 2006, 73, 024205.

(44) Winter, B.; Faubel, M. Chem. Rev. 2006, 106, 1176.

(45) Laage, D.; Hynes, J. T. Science 2006, 311, 832.

(46) Lenz, A.; Ojamae, L. J. Phys. Chem. A 2006, 110, 13388. 
(47) Auer, B.; Kumar, R.; Schmidt, J. R.; Skinner, J. L. Proc. Natl. Acad. Sci. U.S.A. 2007, 104, 14215.

(48) Fuchs, O.; Zharnikov, M.; Weinhardt, L.; Blum, M.; Weigand, M.; Zubavichus, Y.; Bar, M.; Maier, F.; Denlinger, J. D.; Heske, C.; Grunze, M.; Umbach, E. Phys. Rev. Lett. 2008, 100, 027801.

(49) Hartt, G. M.; Shields, G. C.; Kirschner, K. N. J. Phys. Chem. A 2008, 112, 4490.

(50) Santra, B.; Michaelides, A.; Fuchs, M.; Tkatchenko, A.; Filippi, C.; Scheffler, M. J. Chem. Phys. 2008, 129, 194111.

(51) Bryantsev, V. S.; Diallo, M. S.; van Duin, A. C. T.; Goddard, W. A. J. Chem. Theory Comput. 2009, 5, 1016.

(52) Lehmann, S. B. C.; Spickermann, C.; Kirchner, B. J. Chem. Theory Comput. 2009, 5, 1640.

(53) Santra, B.; Michaelides, A.; Scheffler, M. J. Chem. Phys. 2009, $131,124509$.

(54) Loboda, O.; Goncharuk, V. Chem. Phys. Lett. 2010, 484, 144.

(55) Bertrand, G. J. Mol. Liq. 2002, 101, 219.

(56) Head-Gordon, T.; Hura, G. Chem. Rev. 2002, 102, 2651.

(57) Hura, G.; Russo, D.; Glaeser, R. M.; Head-Gordon, T.; Krack, M.; Parrinello, M. Phys. Chem. Chem. Phys. 2003, 5, 1981.

(58) Eaves, J. D.; Loparo, J. J.; Fecko, C. J.; Roberts, S. T.; Tokmakoff, A.; Geissler, P. L. Proc. Natl. Acad. Sci. U.S.A. 2005, 102, 13019.

(59) Smith, J. D.; Cappa, C. D.; Wilson, K. R.; Cohen, R. C.; Geissler, P. L.; Saykally, R. J. Proc. Natl. Acad. Sci. U.S.A. 2005, 102, 14171.

(60) Mantz, Y. A.; Chen, B.; Martyna, G. J. J. Phys. Chem. B 2006, 110,3540 .

(61) Head-Gordon, T.; Johnson, M. E. Proc. Natl. Acad. Sci. U.S.A. 2006, 103, 7973.

(62) Leetmaa, M.; Ljungberg, M.; Ogasawara, H.; Odelius, M.; Naslund, L. A.; Nilsson, A.; Pettersson, L. G. M. J. Chem. Phys. 2006, $125,244510$.

(63) Kumar, R.; Schmidt, J. R.; Skinner, J. L. J. Chem. Phys. 2007, $126,12$.

(64) Shields, G. C.; Kirschner, K. N. Synth. React. Inorg. Met.-Org. Chem. 2008, 38, 32.

(65) Lu, H. G.; Wang, Y. K.; Wu, Y. B.; Yang, P.; Li, L. M.; Li, S. D. J. Chem. Phys. 2008, 129, 124512.

(66) Bickmore, B. R.; Rosso, K. M.; Brown, I. D.; Kerisit, S. J. Phys. Chem. A 2009, 113, 1847.

(67) Wikfeldt, K. T.; Leetmaa, M.; Ljungberg, M. P.; Nilsson, A.; Pettersson, L. G. M. J. Phys. Chem. B 2009, 113, 6246.

(68) Donchev, A. G.; Galkin, N. G.; Illarionov, A. A.; Khoruzhii, O. V.; Olevanov, M. A.; Ozrin, V.D.; Subbotin, M. V.; Tarasov, V. I. Proc. Natl. Acad. Sci. U.S.A. 2006, 103, 8613.

(69) Guillot, B. J. Mol. Liq. 2002, 101, 219.

(70) Burnham, C. J.; Xantheas, S. S.; Miller, M. A.; Applegate, B. E.; Miller, R. E. J. Chem. Phys. 2002, 117, 1109.

(71) Kabrede, H.; Hentschke, R. J. Phys. Chem. B 2003, 107, 3914.

(72) James, T.; Wales, D. J.; Hernandez-Rojas, J. Chem. Phys. Lett. 2005, 415, 302.

(73) Takeuchi, H. J. Chem. Inf. Model 2008, 48, 2226.

(74) Bandow, B.; Hartke, B. J. Phys. Chem. A 2006, 110, 5809.

(75) Burnham, C. J.; Xantheas, S. S. J. Chem. Phys. 2002, 116, 1479.

(76) Burnham, C. J.; Xantheas, S. S. J. Chem. Phys. 2002, 116, 1500.

(77) Cui, J.; Liu, H.; Jordan, K. J Phys. Chem. B 2006, 110, 18872.

(78) Kennedy, D.; Norman, C. Science 2005, 309, 75.

(79) Bukowski, R.; Szalewicz, K.; Groenenboom, G. C.; van der Avoird, A. Science 2007, 315, 1249.

(80) Szalewicz, K.; Leforestier, C.; van der Avoird, A. Chem. Phys. Lett. 2009, 482, 1.

(81) Santra, B.; Michaelides, A.; Scheffler, M. J. Chem. Phys. 2007, 127, 184104.

(82) Pedulla, J. M.; Villa, F.; Jordan, K. D. J. Chem. Phys. 1996, 105, 11091

(83) Schutz, M.; Rauhut, G.; Werner, H. J. J. Phys. Chem. A 1998, $102,5997$.

(84) Su, J. T.; Xu, X.; Goddard, W. A. J. Phys. Chem. A 2004, 108,10518 .
(85) Hodges, M. P.; Stone, A. J.; Xantheas, S. S. J. Phys. Chem. A $1997,101,9163$.

(86) Xantheas, S. S. Chem. Phys. 2000, 258, 225.

(87) Xantheas, S. S.; Dunning, T. H. J. Chem. Phys. 1993, 99, 8774.

(88) Xantheas, S. S. J. Chem. Phys. 1994, 100, 7523.

(89) Xantheas, S. S. J. Chem. Phys. 1995, 102, 4505

(90) Xantheas, S. S. Philos. Mag. B. 1996, 73, 107.

(91) Xantheas, S. S.; Burnham, C. J.; Harrison, R. J. J. Chem. Phys. 2002, 116, 1493.

(92) Xantheas, S.; Apra, E. J. Chem. Phys. 2004, 120, 823.

(93) Xantheas, S. S. Interaction Potentials for Water from Accurate Cluster Calculations. In Intermolecular Forces and Clusters II, 2005; Vol. 116; 119.

(94) Dunning, T. J. Chem. Phys. 1989, 90, 1007.

(95) Kendall, R.; Dunning, T.; Harrison, R. J. Chem. Phys. 1992, 96, 6796.

(96) Cramer, C. J. Essentials of Computational Chemistry: Theories and Models, 2nd ed.; John Wiley \& Sons, Inc.: New York, 2004.

(97) Boys, S. F.; Bernardi, F. Mol. Phys. 1970, 19, 533.

(98) Morrell, T. E.; Shields, G. C. J. Phys. Chem. A 2010, 114, 4266.

(99) Xantheas, S. S.; Dunning, T. H. J. Chem. Phys. 1993, 98, 8037.

(100) Xantheas, S. S. J. Chem. Phys. 1995, 102, 4505.

(101) Feyereisen, M.; Fitzgerald, G.; Komornicki, A. Chem. Phys. Lett. 1993, 208, 359.

(102) Bernholdt, D. E.; Harrison, R. J. Chem. Phys. Lett. 1996, $250,477$.

(103) Marshall, M. S.; Sears, J. S.; Burns, L. A.; Bredas, J. L.; Sherrill, C. D. J. Chem. Theory Comput. 2010, 6, 3681.

(104) Kossmann, S.; Neese, F. Chem. Phys. Lett. 2009, 481, 240.

(105) Kossmann, S.; Neese, F. J. Chem. Theory Comput. 2010, 6, 2325.

(106) Weigend, F.; Kohn, A.; Hattig, C. J. Chem. Phys. 2002, 116,3175 .

(107) Temelso, B.; Shields, G. C. J. Chem. Theory Comput. 2011, 7, 2804.

(108) Shields, R. M.; Temelso, B.; Archer, K. A.; Morrell, T. E.; Shields, G. C. J. Phys. Chem. A 2010, 114, 11725.

(109) Day, M. B.; Kirschner, K. N.; Shields, G. C. J. Phys. Chem. A 2005, 109, 6773.

(110) Bates, D. M.; Tschumper, G. S. J. Phys. Chem. A 2009, 113, 3555.

(111) Chen, Y.; Li, H. J. Phys. Chem. A 2010, 114, 11719.

(112) Weigend, F.; Haser, M. Theor. Chem. Acc. 1997, 97, 331.

(113) Klopper, W. J. Chem. Phys. 1995, 102, 6168.

(114) Xantheas, S. S. J. Chem. Phys. 1996, 104, 8821.

(115) Halkier, A.; Helgaker, T.; Jorgensen, P.; Klopper, W.; Koch, H.; Olsen, J.; Wilson, A. K. Chem. Phys. Lett. 1998, 286, 243.

(116) Halkier, A.; Helgaker, T.; Jorgensen, P.; Klopper, W.; Olsen, J. Chem. Phys. Lett. 1999, 302, 437.

(117) Xantheas, S. S.; Apra, E. J. Chem. Phys. 2004, 120, 823.

(118) Jurecka, P.; Hobza, P. Chem. Phys. Lett. 2002, 365, 89.

(119) Pettersen, E. F.; Goddard, T. D.; Huang, C. C.; Couch, G. S.; Greenblatt, D. M.; Meng, E. C.; Ferrin, T. E. J. Comput. Chem. 2004, $25,1605$.

(120) Barone, V. J. Chem. Phys. 2004, 120, 3059.

(121) Truhlar, D. G.; Isaacson, A. D. J. Chem. Phys. 1991, 94, 357.

(122) Halkier, A.; Klopper, W.; Helgaker, T.; Jorgensen, P.; Taylor, P. R. J. Chem. Phys. 1999, 111, 9157.

(123) Lee, T.; Taylor, P. Int. J. Quantum Chem. 1989, 199.

(124) Fanourgakis, G. S.; Apra, E.; Xantheas, S. S. J. Chem. Phys. 2004, 121, 2655.

(125) Klopper, W.; Schutz, M.; Luthi, H. P.; Leutwyler, S. J. Chem. Phys. 1995, 103, 1085.

(126) Dyke, T. R.; Muenter, J. S. J. Chem. Phys. 1972, 57, 5011.

(127) Tschumper, G. S.; Leininger, M. L.; Hoffman, B. C.; Valeev, E. F.; Schaefer, H. F.; Quack, M. J. Chem. Phys. 2002, 116, 690.

(128) Klopper, W.; van Duijneveldt-van de Rijdt, J. G. C. M.; van Duijneveldt, F. B. Phys. Chem. Chem. Phys. 2000, 2, 2227. 
(129) Lane, J. R.; Kjaergaard, H. G. J. Chem. Phys. 2009, 131, 034307.

(130) Rocher-Casterline, B. E.; Ch'ng, L. C.; Mollner, A. K.; Reisler, H. J. Chem. Phys. 2011, 134, 211101.

(131) Shank, A.; Wang, Y.; Kaledin, A.; Braams, B. J.; Bowman, J. M. J. Chem. Phys. 2009, 130, 144314.

(132) Curtiss, L. A.; Frurip, D. J.; Blander, M. J. Chem. Phys. 1979, $71,2703$.

(133) Goldman, N.; Fellers, R. S.; Leforestier, C.; Saykally, R. J. J. Phys. Chem. A 2001, 105, 515.

(134) Losada, M.; Leutwlyer, S. J. Chem. Phys. 2002, 117, 2003.

(135) Pedulla, J. M.; Jordan, K. D. Accurate Calculation of the Interaction Energies in Hydrogen-Bonded Complexes. In Recent Theoretical and Experimental Advances in Hydrogen Bonded Clusters; Xantheas, S. S., Ed.; Kluwer Academic Publishers: Netherlands, 2000; p 35.

(136) Liu, K.; Brown, M. G.; Carter, C.; Saykally, R. J.; Gregory, J. K.; Clary, D. C. Nature 1996, 381, 501.

(137) Day, M. B.; Kirschner, K. N.; Shields, G. C. Int. J. Quantum Chem. 2005, 102, 565.

(138) Buck, U.; Ettischer, I.; Melzer, M.; Buch, V.; Sadlej, J. Phys. Rev. Lett. 1998, 80, 2578.

(139) Gruenloh, C. J.; Carney, J. R.; Arrington, C. A.; Zwier, T. S.; Fredericks, S. Y.; Jordan, K. D. Science 1997, 276, 1678.

(140) Gruenloh, C. J.; Carney, J. R.; Hagemeister, F. C.; Zwier, T. S.; Wood, J. T.; Jordan, K. D. J. Chem. Phys. 2000, 113, 2290.

(141) Evans, G. T.; Vaida, V. J. Chem. Phys. 2000, 113, 6652.

(142) Pfeilsticker, K.; Lotter, A.; Peters, C.; Bösch, H. Science 2003, 300, 2078.

(143) Dunn, M. E.; Pokon, E. K.; Shields, G. C. J. Am. Chem. Soc. 2004, 126, 2647.

(144) Shillings, A. J. L.; Ball, S. M.; Barber, M. J.; Tennyson, J.; Jones, R. L. Atmos. Chem. Phys. Discuss. 2010, 10, 23345.

(145) Vaida, V.; Daniel, J. S.; Kjaergaard, H. G.; Goss, L. M.; Tuck, A. F. Q. J. R. Meteorol. Soc. 2001, 127, 1627.

(146) Vaida, V.; Kjaergaard, H. G.; Feierabend, K. J. Int. Rev. Phys. Chem. 2003, 22, 203.

(147) Ptashnik, I. V. J. Quant. Spectrosc. Radiat. Transfer 2008, 109, 831.

(148) Stull, R. B. Meterology for Scientists and Engineers, 2nd ed.; Brooks/Cole: Pacific Grove, CA, 2000. 


\title{
Supporting Information for:
}

\section{Benchmark Structures and Binding Energies of}

\section{Small Water Clusters with Anharmonicity \\ Corrections}

\author{
Berhane Temelso, Kaye A. Archer ${ }^{+}$and George C. Shields ${ }^{*}$ \\ Dean's Office, College of Arts and Sciences, and \\ Department of Chemistry \\ Bucknell University \\ Lewisburg, PA 17837
}

October 3, 2011

* Carrespondence: gearge.shields 回bucknell.edu 


\section{INDEX}

Table S1: Difference in geometry and binding energy between RI-MP2/aVDZ and RIMP2/aVTZ levels of theory for $(\mathrm{H} 2 \mathrm{O}) \mathrm{n}=2-6$

Table S2. Scaling factors for the MP2/aug-cc-pVDZ harmonic ZPVE of water clusters. ${ }^{a, b}$

Table S3. Frequency scaling factors for $\Delta \mathrm{H}_{\mathrm{vib}}(\mathrm{T})$ for water clusters at the MP2/aug-ccpVDZ level of theory. ${ }^{\mathrm{a}}$.....

Table S4. Frequency scaling factors for $\mathrm{S}_{\mathrm{vib}}(\mathrm{T})$ for water clusters at the MP2/aug-ccpVDZ level of theory. ${ }^{\mathrm{a}}$

Table 5: RI-MP2 energy and CCSD(T) correction to the binding energy of $\left(\mathrm{H}_{2} \mathrm{O}\right)_{\mathrm{n}=1-10} \ldots 8$

Figure S1. Error in the RI-MP2/aVDZ binding energies as a result of the RI approximation for $\left(\mathrm{H}_{2} \mathrm{O}\right)_{\mathrm{n}=2-10}$. 
Table S1: Difference in geometry and binding energy between RI-MP2/aVDZ and RIMP2/aVTZ levels of theory for $(\mathrm{H} 2 \mathrm{O}) \mathrm{n}=2-6$

\begin{tabular}{|c|c|c|c|c|}
\hline & & 2 Bindir & gy $(\mathrm{kcal} / \mathrm{mol})$ & RMSD \\
\hline & $\overline{\mathrm{aVTZ} / / \mathrm{aVDZ}}{ }^{\mathrm{a}}$ & aVTZ & aVTZ- aVTZ//aVDZ & $(\mathrm{A})^{\mathrm{b}}$ \\
\hline $2-C_{s}$ & -5.19 & -5.18 & 0.00 & 0.005 \\
\hline $3-\mathrm{C}_{1}$ & -16.14 & -16.30 & -0.16 & 0.090 \\
\hline $3-\mathrm{C}_{3}$ & -15.55 & -15.54 & 0.00 & 0.011 \\
\hline $4-S_{4}$ & -28.54 & -28.54 & 0.01 & 0.023 \\
\hline $4-C_{i}$ & -27.71 & -27.71 & 0.01 & 0.011 \\
\hline $\begin{array}{l}4- \\
\mathrm{C}_{1}(\text { Pyramid })\end{array}$ & -24.66 & -25.01 & -0.35 & 0.092 \\
\hline 5- $\mathrm{C}_{1}($ Cyclic $)$ & -37.52 & -37.54 & -0.01 & 0.024 \\
\hline $6-\mathrm{C}_{1}($ Prism $)$ & -47.80 & -47.96 & -0.16 & 0.071 \\
\hline $6-\mathrm{C}_{1}$ (Cage) & -47.81 & -47.84 & -0.03 & 0.031 \\
\hline $6-\mathrm{C}_{1}($ Book $)$ & -47.51 & -47.49 & 0.02 & 0.012 \\
\hline $6-\mathrm{S}_{6}(\mathrm{Cyclic})$ & -46.27 & -46.25 & 0.02 & 0.013 \\
\hline
\end{tabular}


Table S2. Scaling factors for the MP2/aug-cc-pVDZ harmonic ZPVE of water clusters. ${ }^{a, b}$

\begin{tabular}{|c|c|c|c|}
\hline & ZPVE ${ }^{\text {harmonic }}$ & $\mathrm{ZPVE}^{\text {anharmonic c }}$ & $\mathrm{ZPVE}^{\text {anharmonic }} / \mathrm{ZPVE}^{\text {harmonic }}$ \\
\hline $2-C_{s}$ & 28.88 & 28.23 & 0.978 \\
\hline 3-UUD & 45.50 & 44.31 & 0.974 \\
\hline 4- $C_{i}$ & 61.59 & 60.19 & 0.977 \\
\hline 4- $\mathrm{S}_{4}$ & 61.78 & 60.27 & 0.976 \\
\hline 5-Cyclic & 77.36 & 75.40 & 0.975 \\
\hline 6-Book-1 & 93.59 & 91.20 & 0.974 \\
\hline 6-Cage & 93.96 & 91.48 & 0.974 \\
\hline 6-Prism & 94.16 & 91.78 & 0.975 \\
\hline 6-Bag & 93.38 & 90.95 & 0.974 \\
\hline $8-\mathrm{S}_{4}$ & 127.57 & 124.76 & 0.978 \\
\hline $8-\mathrm{D}_{2 \mathrm{~d}}$ & 127.57 & 124.90 & 0.979 \\
\hline$\lambda$ & & & 0.976 \\
\hline$\sigma(\lambda)$ & & & 0.002 \\
\hline RMSE/cluster & & & 0.18 \\
\hline
\end{tabular}

\footnotetext{
${ }^{a}$ Four hexamers (cyclic ring, book-2, cyclic boat-1 and cyclic boat-2) and are excluded because they had individual scaling factors $\left(\lambda_{\mathrm{i}}=v_{\mathrm{i}} / \omega_{\mathrm{i}}\right)$ that lie outside $3 \sigma$ of the average $\lambda$.

${ }^{\mathrm{b}}$ in $\mathrm{kcal} / \mathrm{mol}$

${ }^{c}$ calculated using Equation (7) in Reference
} 
Table S3. Frequency scaling factors for $\Delta \mathrm{H}_{\mathrm{vib}}(\mathrm{T})$ for water clusters at the MP2/aug-ccpVDZ level of theory. ${ }^{\mathrm{a}}$

\begin{tabular}{llll}
\hline $\mathrm{T}(\mathrm{K})$ & Scaling Factor $\left(\lambda_{\mathrm{H}}\right)$ & Uncertainty $\left[\sigma\left(\lambda_{\mathrm{H}}\right)\right]$ & RMSE $(\mathrm{kcal} / \mathrm{mol})$ \\
\hline 50 & 0.806 & 0.117 & 0.00 \\
100 & 0.835 & 0.087 & 0.00 \\
150 & 0.851 & 0.069 & 0.01 \\
200 & 0.860 & 0.055 & 0.01 \\
250 & 0.865 & 0.045 & 0.01 \\
273.15 & 0.866 & 0.042 & 0.01 \\
298.15 & 0.868 & 0.039 & 0.01 \\
300 & 0.868 & 0.039 & 0.01 \\
350 & 0.871 & 0.034 & 0.01 \\
373.15 & 0.872 & 0.033 & 0.01 \\
\hline
\end{tabular}

\footnotetext{
${ }^{\mathrm{a}}$ Using 703 frequencies after removing outliers from an initial set of 723 frequencies.
} 
Table S4. Frequency scaling factors for $\mathrm{S}_{\mathrm{vib}}(\mathrm{T})$ for water clusters at the MP2/aug-ccpVDZ level of theory. ${ }^{\mathrm{a}}$

\begin{tabular}{llll}
\hline $\mathrm{T}(\mathrm{K})$ & Scaling Factor $\left(\lambda_{\mathrm{S}}\right)$ & Uncertainty $\left[\sigma\left(\lambda_{\mathrm{S}}\right)\right]$ & RMSE $(\mathrm{cal} / \mathrm{mol} / \mathrm{K})$ \\
\hline 50 & 0.790 & 0.040 & 0.06 \\
100 & 0.815 & 0.028 & 0.08 \\
150 & 0.828 & 0.023 & 0.09 \\
200 & 0.836 & 0.020 & 0.10 \\
250 & 0.841 & 0.018 & 0.10 \\
273.15 & 0.843 & 0.017 & 0.11 \\
298.15 & 0.844 & 0.016 & 0.11 \\
300 & 0.844 & 0.016 & 0.11 \\
350 & 0.847 & 0.015 & 0.11 \\
373.15 & 0.848 & 0.014 & 0.11 \\
\hline
\end{tabular}

\footnotetext{
${ }^{a}$ Using 703 frequencies after removing outliers from an initial set of 723 frequencies.
} 


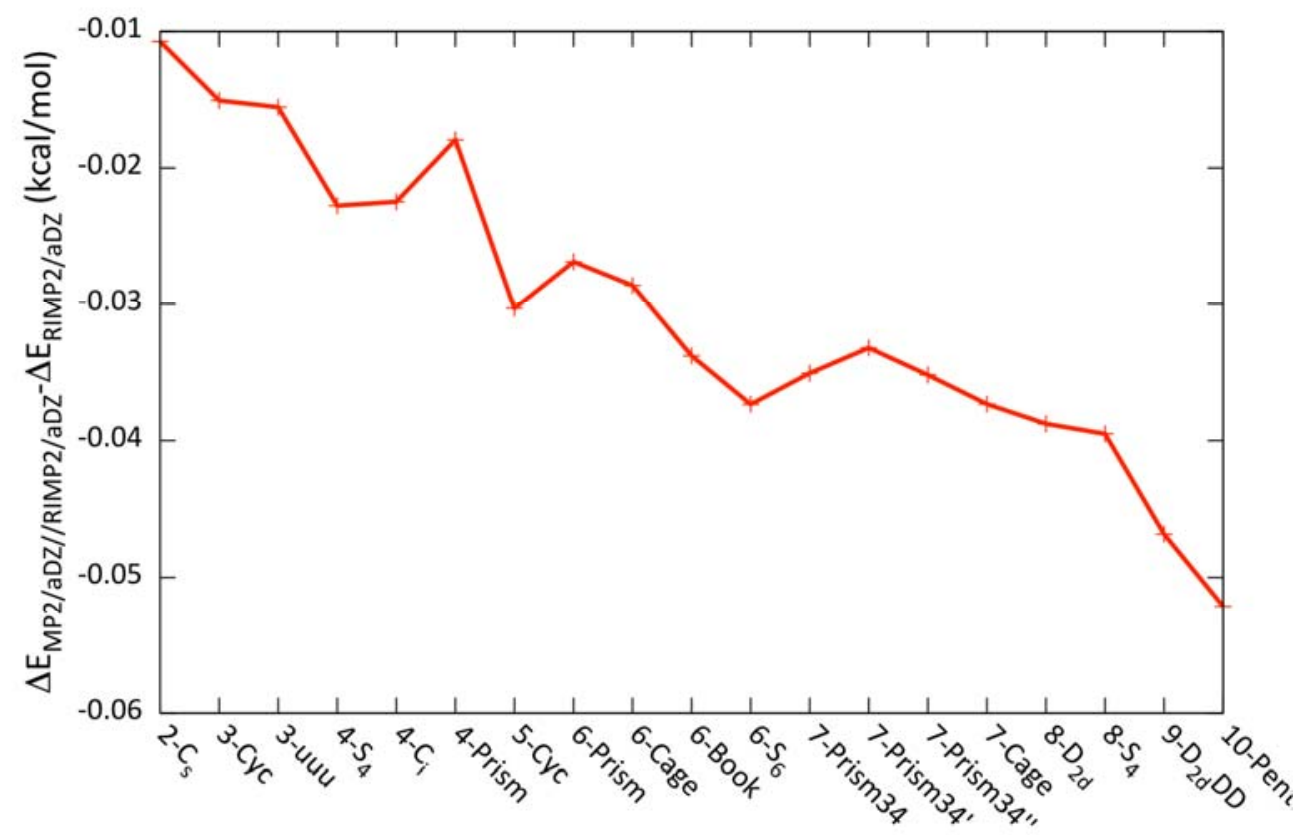

Figure S1. Error in the RI-MP2/aVDZ binding energies as a result of the RI approximation for $\left(\mathrm{H}_{2} \mathrm{O}\right)_{\mathrm{n}=2-10}$. 
Table 5: RI-MP2 energy and CCSD(T) correction to the binding energy of $\left(\mathrm{H}_{2} \mathrm{O}\right)_{\mathrm{n}=1-10}$.

\begin{tabular}{|c|c|c|c|c|c|c|}
\hline $\mathrm{H} 2 \mathrm{O}$ & & \multicolumn{4}{|c|}{ E[RI-MP2] (a.u.) } & $\mathrm{kcal} / \mathrm{mol}$ \\
\hline $\mathrm{N}$ & Isomer & aVDZ & aVTZ & aVQZ & $\begin{array}{l}\text { CBS(4- } \\
\text { 5poly) }\end{array}$ & $\delta_{M P 2}^{C C S D(T)}$ \\
\hline 1 & $\mathrm{C} 2 \mathrm{v}$ & -76.260901 & -76.328933 & -76.351815 & -76.370581 & - \\
\hline 2 & Cs & -152.530190 & -152.666132 & -152.711758 & -152.749123 & -0.03 \\
\hline 3 & UUD & -228.808512 & -229.012519 & -229.080878 & -229.136798 & 0.02 \\
\hline 3 & UUU & -228.807609 & -229.011573 & -229.079955 & -229.135914 & 0.08 \\
\hline 4 & S4 & -305.089279 & -305.361216 & -305.452127 & -305.526378 & 0.21 \\
\hline 4 & $\mathrm{Ci}$ & -305.087964 & -305.359896 & -305.450793 & -305.525027 & 0.22 \\
\hline 4 & Py & -305.083343 & -305.355036 & -305.445959 & -305.520274 & -0.07 \\
\hline 5 & $\mathrm{CYC}$ & -381.364549 & -381.704518 & -381.818120 & -381.910877 & 0.37 \\
\hline 5 & CA-A & -381.362108 & -381.701638 & -381.815129 & -381.907815 & -0.08 \\
\hline 5 & CA-B & -381.361005 & -381.700506 & -381.813933 & -381.906536 & -0.17 \\
\hline 5 & $\mathrm{CA}-\mathrm{C}$ & -381.362394 & -381.701938 & -381.815395 & -381.908032 & -0.10 \\
\hline 5 & FR-A & -381.360080 & -381.699548 & -381.813010 & -381.905669 & -0.02 \\
\hline 5 & FR-B & -381.362623 & -381.702302 & -381.815859 & -381.908608 & 0.08 \\
\hline 5 & FR-C & -381.358797 & -381.698413 & -381.811900 & -381.904564 & -0.02 \\
\hline 6 & $\mathrm{BAG}$ & -457.640619 & -458.047968 & -458.183973 & -458.294962 & 0.26 \\
\hline 6 & BK-1 & -457.641774 & -458.049317 & -458.185387 & -458.296426 & 0.26 \\
\hline 6 & BK-2 & -457.641372 & -458.048868 & -458.184876 & -458.295839 & 0.26 \\
\hline 6 & $\mathrm{CA}$ & -457.642568 & -458.049952 & -458.185879 & -458.296753 & 0.05 \\
\hline 6 & CB-1 & -457.638095 & -458.046013 & -458.182352 & -458.293693 & 0.49 \\
\hline 6 & CB-2 & -457.637902 & -458.045864 & -458.182223 & -458.293581 & 0.47 \\
\hline 6 & $\mathrm{CC}$ & -457.639652 & -458.047556 & -458.183936 & -458.295335 & 0.48 \\
\hline 6 & PR & -457.642962 & -458.050082 & -458.185961 & -458.296817 & -0.13 \\
\hline 7 & PR3 & -533.922311 & -534.397295 & -534.555680 & -534.684819 & 0.05 \\
\hline
\end{tabular}




\begin{tabular}{|l|l|l|l|l|l|l|}
\hline 7 & BI2 & -533.915986 & -534.391420 & -534.550087 & -534.679529 & 0.30 \\
\hline 7 & BI1 & -533.916058 & -534.391503 & -534.550171 & -534.679614 & 0.28 \\
\hline 7 & PR1 & -533.923154 & -534.398088 & -534.556447 & -534.685561 & 0.04 \\
\hline 7 & CH3 & -533.915169 & -534.390769 & -534.549565 & -534.679152 & 0.32 \\
\hline 7 & CH2 & -533.916849 & -534.392332 & -534.551025 & -534.680495 & 0.37 \\
\hline 7 & CA2 & -533.918938 & -534.394092 & -534.552558 & -534.681777 & 0.16 \\
\hline 7 & HM1 & -533.913631 & -534.389198 & -534.548187 & -534.678045 & 0.35 \\
\hline 7 & CA1 & -533.920289 & -534.395400 & -534.553866 & -534.683091 & 0.18 \\
\hline 7 & PR2 & -533.922623 & -534.397578 & -534.555937 & -534.685047 & -0.01 \\
\hline 7 & CH1 & -533.917552 & -534.393067 & -534.551809 & -534.681339 & 0.38 \\
\hline 8 & D2d & -610.210435 & -610.752852 & -610.933366 & -611.080350 & 0.06 \\
\hline 8 & S4 & -610.210494 & -610.752872 & -610.933407 & -611.080428 & 0.09 \\
\hline 9 & D2dDD & -686.486919 & -687.097284 & -687.300396 & -687.465772 & 0.21 \\
\hline 9 & S4DA & -686.486557 & -687.096883 & -687.300003 & -687.465400 & 0.22 \\
\hline 10 & PP1 & -762.767106 & -763.445328 & -763.670738 & -763.854115 & 0.18 \\
\hline 10 & PP2 & -762.766905 & -763.445112 & -763.670573 & -763.854023 & 0.12 \\
\hline
\end{tabular}




\section{RI-MP2/aVDZ Optimized Coordinates}

(See Table 5 for Energies)

6

2_Cs FINAL SINGLE POINT ENERGY $\quad-152.5301$

$\mathrm{H} \quad-0.6305 \quad-0.8758 \quad 0.2588$

O $\quad-1.5614 \quad-0.8255 \quad 0.5368$

H $\quad-1.9991 \quad-1.5191 \quad 0.0288$

O $\quad 1.2821 \quad-0.7524 \quad-0.1108$

H $\quad 1.5168 \quad 0.1326 \quad-0.4203$

H $\quad 1.7973 \quad-0.8645 \quad 0.6993$

9

3_UUD FINAL SINGLE POINT ENERGY -228.8085

H $\quad 8.8983 \quad-2.2843 \quad-0.1789$

$\begin{array}{llll}\text { O } & 7.9708 & -1.9757 & -0.1200\end{array}$

H $\quad 7.5408 \quad-2.5819 \quad 0.4951$

O $\quad 10.7652 \quad-1.9603 \quad-0.2644$

H $\quad 10.5807 \quad-1.0101 \quad-0.1202$

H $\quad 11.2830 \quad-2.2241 \quad 0.5066$

$\begin{array}{llll}\mathrm{O} & 9.3715 & 0.4200 & 0.2688\end{array}$

H $\quad 8.6226 \quad-0.2038 \quad 0.1882$

H $\quad 9.1408 \quad 1.1658-0.2985$

9

3_UUU FINAL SINGLE POINT ENERGY $\quad-228.8076$

$\begin{array}{llll}\mathrm{H} & 16.8087 & -2.8031 & 0.4083\end{array}$ 


$\begin{array}{llll}\mathrm{O} & 17.4455 & -2.3397 & -0.1484 \\ \mathrm{H} & 19.3558 & -2.1576 & -0.1032 \\ \mathrm{H} & 17.3389 & -1.3930 & 0.0703 \\ \mathrm{O} & 18.1291 & 0.3493 & 0.2276 \\ \mathrm{O} & 20.1375 & -1.5710 & -0.1160 \\ \mathrm{H} & 20.8092 & -2.0300 & 0.4019 \\ \mathrm{H} & 18.1476 & 1.0095 & 0.9304 \\ \mathrm{H} & 19.0240 & -0.0436 & 0.2185\end{array}$

12

4_S4 FINAL SINGLE POINT ENERGY -305.0892

$\mathrm{H} \quad-1.5581 \quad-11.1808 \quad-1.1059$

O $\quad-1.1399-10.9662 \quad-0.2631$

H $\quad 0.6279-11.0666 \quad-0.0924$

H $\quad-1.3031 \quad-10.0027 \quad-0.1396$

$\begin{array}{llll}\text { O } & 1.5855 & -10.9278 & 0.0923\end{array}$

H $\quad 1.7974-11.5649 \quad 0.7855$

H $\quad 1.6475 \quad-9.1832 \quad 0.4342$

O $\quad 1.4893 \quad-8.2153 \quad 0.5263$

H $\quad 2.1312 \quad-7.8035 \quad-0.0651$

H $\quad-0.2513 \quad-8.0909 \quad 0.1807$

O $\quad \begin{array}{llll}-1.2137 & -8.2339 & 0.0270\end{array}$

$\mathrm{H} \quad-1.6492 \quad-7.7945 \quad 0.7678$

12

4_Ci FINAL SINGLE POINT ENERGY -305.0879

H $\quad 11.3431 \quad-11.5500 \quad 0.6239$ 


$\begin{array}{lllll}\mathrm{O} & 11.0860 & -10.8833 & -0.0246 \\ \mathrm{H} & 11.1635 & -9.1700 & 0.4410 \\ \mathrm{H} & 10.1245 & -11.0305 & -0.1756 \\ \mathrm{O} & 11.0065 & -8.2255 & 0.6727 \\ \mathrm{H} & 11.6828 & -7.7349 & 0.1903 \\ \mathrm{H} & 9.2501 & -8.0404 & 0.3675 \\ \mathrm{O} & 8.2886 & -8.1876 & 0.2161 \\ \mathrm{H} & 8.0320 & -7.5214 & -0.4330 \\ \mathrm{H} & 8.2110 & -9.9012 & -0.2486 \\ \mathrm{O} & 8.3679 & -10.8457 & -0.4800 \\ \mathrm{H} & 7.6919 & -11.3362 & 0.0031\end{array}$

12

4_py FINAL SINGLE POINT ENERGY -305.0833

H $\quad 20.2369 \quad-9.3309 \quad-0.0401$

O $\quad 20.5295 \quad-10.0740 \quad 0.5233$

H $\quad 17.4282 \quad-9.5242 \quad 1.5646$

H $\quad 21.4773 \quad-9.9463 \quad 0.6476$

O $\quad 17.1291 \quad-9.5466 \quad 0.6461$

H $\quad 17.4818-10.3922 \quad 0.2939$

H $\quad 18.1846 \quad-8.6176 \quad-0.4829$

O $\quad 18.9262 \quad-8.4709 \quad-1.1140$

$\mathrm{H} \quad 18.8052 \quad-7.5802 \quad-1.4631$

$\mathrm{H} \quad \begin{array}{llll}18.5517 & -10.7990 & -1.5917\end{array}$

O $\quad 18.5172-11.4816 \quad-0.9040$

H $\quad 19.3711 \quad-11.3530 \quad-0.4511$ 


$$
\begin{array}{llll}
\text { 15 } & & & \\
\text { 5_CYC } & & & \\
\mathrm{H} & -1.6915 & -20.5421 & 0.0681 \\
\mathrm{H} & 1.7816 & -21.8846 & -0.0554 \\
\mathrm{O} & -1.3117 & -21.3989 & -0.2397 \\
\mathrm{O} & -2.2679 & -18.9751 & 0.5686 \\
\mathrm{H} & -1.5476 & -18.3048 & 0.6316 \\
\mathrm{H} & -2.7491 & -18.9036 & 1.4014 \\
\mathrm{O} & -0.1623 & -17.2162 & 0.6719 \\
\mathrm{H} & 0.0828 & -16.7769 & 1.4952 \\
\mathrm{H} & 0.6608 & -17.6795 & 0.3856 \\
\mathrm{O} & 2.0762 & -18.5774 & -0.0947 \\
\mathrm{H} & 1.8679 & -19.5272 & -0.2618 \\
\mathrm{H} & 2.5246 & -18.2816 & -0.8964 \\
\mathrm{O} & 1.3840 & -21.1708 & -0.5683 \\
\mathrm{H} & 0.4105 & -21.2954 & -0.4670 \\
\mathrm{H} & -1.8524 & -21.6491 & -0.9987
\end{array}
$$

15

5_FR-B

$$
\begin{array}{llll}
\mathrm{H} & 7.6783 & -20.0517 & 0.4265 \\
\mathrm{H} & 8.5970 & -17.7632 & 0.0996 \\
\mathrm{O} & 7.8111 & -19.2534 & 0.9959 \\
\mathrm{O} & 7.7349 & -21.4760 & -0.5605 \\
\mathrm{H} & 8.6853 & -21.7392 & -0.5904 \\
\mathrm{H} & 7.4849 & -21.3733 & -1.4873 \\
\mathrm{O} & 10.4393 & -21.8462 & -0.6341
\end{array}
$$




$$
\begin{array}{llll}
\mathrm{H} & 10.9423 & -22.5343 & -0.1822 \\
\mathrm{H} & 10.6912 & -21.0044 & -0.1845 \\
\mathrm{O} & 10.7433 & -19.4866 & 0.7160 \\
\mathrm{H} & 10.5950 & -18.6825 & 0.1835 \\
\mathrm{H} & 9.9168 & -19.5216 & 1.2264 \\
\mathrm{O} & 9.2970 & -17.2614 & -0.3622 \\
\mathrm{H} & 9.3022 & -16.3947 & 0.0623 \\
\mathrm{H} & 7.0844 & -19.2680 & 1.6300
\end{array}
$$

15

\section{CA-C}

$\begin{array}{llll}\mathrm{H} & 19.1476 & -18.6179 & 1.9704 \\ \mathrm{H} & 18.5893 & -21.2331 & -0.8702 \\ \mathrm{O} & 18.3419 & -18.4787 & 2.4971 \\ \mathrm{O} & 20.0898 & -18.4481 & 0.1161 \\ \mathrm{H} & 19.6712 & -19.1881 & -0.3914 \\ \mathrm{H} & 21.0068 & -18.4174 & -0.1823 \\ \mathrm{O} & 16.5910 & -19.0769 & 0.2857 \\ \mathrm{H} & 17.0307 & -19.0921 & 1.1594 \\ \mathrm{H} & 16.6958 & -18.1410 & 0.0425 \\ \mathrm{O} & 18.0407 & -16.5363 & 0.2537 \\ \mathrm{H} & 18.1251 & -15.6851 & -0.1927 \\ \mathrm{H} & 18.8621 & -17.0260 & 0.0435 \\ \mathrm{O} & 18.5698 & -20.3060 & -1.1391 \\ \mathrm{H} & 17.7484 & -19.9429 & -0.7234 \\ \mathrm{H} & 18.1288 & -17.5553 & 2.2889\end{array}$




$$
\begin{array}{llll}
\text { 15 } & & & \\
\text { 5_CA-A } & & & \\
\text { H } & 28.0952 & -21.0321 & 0.7908 \\
\text { H } & 26.8033 & -19.7975 & -0.5722 \\
\text { O } & 28.2118 & -21.2412 & -0.1571 \\
\text { O } & 27.9947 & -19.6038 & 2.0627 \\
\text { H } & 28.7564 & -19.1661 & 1.6041 \\
\text { H } & 28.1662 & -19.5150 & 3.0077 \\
\text { O } & 29.9149 & -18.7946 & 0.3429 \\
\text { H } & 29.8031 & -19.6171 & -0.1594 \\
\text { H } & 29.4908 & -18.1202 & -0.2313 \\
\text { O } & 28.2731 & -17.1362 & -1.1859 \\
\text { H } & 27.4864 & -17.6798 & -0.9562 \\
\text { H } & 28.2731 & -17.0872 & -2.1495 \\
\text { O } & 26.3647 & -18.9674 & -0.3160 \\
\text { H } & 26.5111 & -18.9618 & 0.6451 \\
\text { H } & 28.1654 & -22.2031 & -0.2198
\end{array}
$$

15

5_CA-B

$$
\begin{array}{llll}
\mathrm{H} & 1.0031 & -29.5392 & -0.4298 \\
\mathrm{H} & 0.4565 & -27.1155 & -0.2358 \\
\mathrm{O} & 1.5044 & -28.8728 & 0.0937 \\
\mathrm{O} & -0.2837 & -30.5703 & -1.1411 \\
\mathrm{H} & -1.0720 & -30.0809 & -0.8198 \\
\mathrm{H} & -0.3707 & -31.4480 & -0.7482 \\
\mathrm{O} & -2.1452 & -28.9330 & 0.1004
\end{array}
$$




$$
\begin{array}{llll}
\mathrm{H} & -3.0674 & -29.0782 & 0.3441 \\
\mathrm{H} & -1.6543 & -28.8240 & 0.9527 \\
\mathrm{O} & -0.4817 & -28.3095 & 2.1685 \\
\mathrm{H} & -0.4237 & -27.4207 & 1.7677 \\
\mathrm{H} & 0.3538 & -28.7024 & 1.8617 \\
\mathrm{O} & -0.2838 & -26.5059 & -0.0673 \\
\mathrm{H} & -1.0485 & -27.0041 & -0.3966 \\
\mathrm{H} & 2.4223 & -28.9619 & -0.1903
\end{array}
$$

15

5_FR-C

$$
\begin{array}{llll}
\mathrm{H} & 9.4222 & -31.1635 & -0.4861 \\
\mathrm{H} & 8.1875 & -27.3637 & -0.4908 \\
\mathrm{O} & 10.3897 & -30.9940 & -0.4973 \\
\mathrm{O} & 7.6136 & -31.2138 & -0.3042 \\
\mathrm{H} & 7.3948 & -30.3551 & 0.1134 \\
\mathrm{H} & 7.3028 & -31.8768 & 0.3251 \\
\mathrm{O} & 7.5008 & -28.6831 & 0.9359 \\
\mathrm{H} & 7.0209 & -28.4541 & 1.7414 \\
\mathrm{H} & 8.4632 & -28.7184 & 1.1896 \\
\mathrm{O} & 10.1712 & -28.6705 & 1.0651 \\
\mathrm{H} & 10.1556 & -27.9842 & 0.3740 \\
\mathrm{H} & 10.4125 & -29.4863 & 0.5751 \\
\mathrm{O} & 8.9550 & -26.9551 & -0.9296 \\
\mathrm{H} & 8.8405 & -26.0079 & -0.7812 \\
\mathrm{H} & 10.5935 & -30.8394 & -1.4284
\end{array}
$$


5_FR-A

$\begin{array}{llll}\mathrm{H} & 19.5355 & -31.3186 & -0.1785 \\ \mathrm{H} & 18.7774 & -27.2247 & -0.7430 \\ \mathrm{O} & 20.4857 & -31.2220 & 0.0437 \\ \mathrm{O} & 17.6859 & -31.1634 & -0.3495 \\ \mathrm{H} & 17.5331 & -30.2224 & -0.1241 \\ \mathrm{H} & 17.1176 & -31.6491 & 0.2608 \\ \mathrm{O} & 17.6878 & -28.4822 & 0.5480 \\ \mathrm{H} & 17.1271 & -28.1207 & 1.2455 \\ \mathrm{H} & 18.5909 & -28.5938 & 0.9549 \\ \mathrm{O} & 20.2743 & -28.6737 & 1.1759 \\ \mathrm{H} & 20.4673 & -28.0420 & 0.4593 \\ \mathrm{H} & 20.5178 & -29.5513 & 0.8105 \\ \mathrm{O} & 19.6476 & -26.8578 & -0.9790 \\ \mathrm{H} & 19.5796 & -25.9213 & -0.7533 \\ \mathrm{H} & 20.6892 & -31.9913 & 0.5894\end{array}$

18

6-PR

$\begin{array}{llll}\mathrm{O} & -1.9241 & -39.9369 & 0.2244\end{array}$

H $\quad \begin{array}{lll}-1.7339 & -40.0619 & -0.7214\end{array}$

H $\quad-2.0308 \quad-38.9602 \quad 0.2590$

O $\quad-1.6252-37.1872 \quad-0.1835$

$\mathrm{H} \quad-1.3632 \quad-37.4801 \quad-1.0740$

$\mathrm{H} \quad-0.7751 \quad-37.0474 \quad 0.2718$

O $\quad-0.7346 \quad-39.0353 \quad-2.2858$ 


$$
\begin{array}{llll}
\mathrm{H} & -0.6724 & -39.1225 & -3.2446 \\
\mathrm{H} & 0.1927 & -39.1034 & -1.9556 \\
\mathrm{O} & 1.6853 & -39.1868 & -1.0050 \\
\mathrm{H} & 1.7953 & -38.3281 & -0.5647 \\
\mathrm{H} & 1.4640 & -39.7654 & -0.2520 \\
\mathrm{O} & 0.4498 & -40.0965 & 1.4209 \\
\mathrm{H} & -0.4725 & -40.1381 & 1.0403 \\
\mathrm{H} & 0.4880 & -40.7832 & 2.0974 \\
\mathrm{O} & 0.9394 & -37.3782 & 1.1917 \\
\mathrm{H} & 1.2480 & -36.8472 & 1.9361 \\
\mathrm{H} & 0.8015 & -38.2813 & 1.5485
\end{array}
$$

18

6-CA

O $\quad 10.1313 \quad-39.6546 \quad-1.2837$

$\mathrm{H} \quad 10.9834 \quad-39.2940 \quad-0.9427$

H $\quad 10.3710 \quad-40.2693 \quad-1.9876$

O $\quad 8.5206 \quad-37.2415 \quad-1.1214$

$\mathrm{H} \quad 8.9694 \quad-38.0370 \quad-1.4609$

H $\quad 7.6674 \quad-37.5876 \quad-0.7864$

O $\quad 10.0161 \quad-37.0305 \quad 1.0891$

H $\quad 9.4323 \quad-36.9616 \quad 0.2835$

$\mathrm{H} \quad 9.9503 \quad-36.1767 \quad 1.5337$

O $\quad 8.7588 \quad-39.6895 \quad 1.2947$

H $\quad 9.2025 \quad-39.9141 \quad 0.4565$

H $\quad 9.1929-38.8551 \quad 1.5467$

O $\quad 12.1674 \quad-38.3372 \quad-0.0356$ 


$$
\begin{array}{lrrr}
\mathrm{H} & 11.5483 & -37.7652 & 0.4699 \\
\mathrm{H} & 12.7194 & -38.7610 & 0.6334 \\
\mathrm{O} & 6.4748 & -38.4556 & 0.3410 \\
\mathrm{H} & 7.1523 & -39.0355 & 0.7568 \\
\mathrm{H} & 5.7121 & -39.0216 & 0.1750
\end{array}
$$

18

6-BK-1

O $\quad 15.9468 \quad-39.5823 \quad 0.5548$

H $\quad 15.3045 \quad-40.0871 \quad 0.0416$

$\begin{array}{llll}\mathrm{H} & 16.8221 & -39.7683 & 0.1280\end{array}$

O $\quad 18.3471 \quad-39.7460 \quad-0.6662$

H $\quad 19.1305-40.0034 \quad-0.1359$

H $\quad \begin{array}{llll}18.5029 & -38.8042 & -0.8557\end{array}$

$\begin{array}{llll}\text { O } & 20.6467 & -40.0714 & 0.9070\end{array}$

H $\quad 21.4549-40.4532 \quad 0.5435$

$\begin{array}{llll}\mathrm{H} & 20.8337 & -39.1110 & 0.9827\end{array}$

O $\quad 20.8368 \quad-37.2970 \quad 0.9070$

H $\quad 20.0333 \quad-37.0136 \quad 0.4221$

H $\quad 20.8440 \quad-36.7677 \quad 1.7135$

$\begin{array}{llll}\text { O } & 16.1147 & -36.8858 & 0.5596\end{array}$

$\begin{array}{llll}\mathrm{H} & 15.9307 & -37.8581 & 0.5885\end{array}$

H $\quad 15.9523 \quad-36.5744 \quad 1.4583$

O $\quad 18.5450 \quad-36.8241 \quad-0.6030$

H $\quad 18.5146 \quad-36.2064 \quad-1.3439$

H $\quad 17.6621 \quad-36.7483 \quad-0.1590$

18 


\begin{tabular}{llll} 
6-BK-2 & & & \\
$\mathrm{O}$ & 29.7954 & -37.1884 & -0.3910 \\
$\mathrm{H}$ & 30.6865 & -36.9230 & -0.1328 \\
$\mathrm{H}$ & 29.8886 & -38.1244 & -0.7014 \\
$\mathrm{O}$ & 29.8265 & -39.8168 & -1.0122 \\
$\mathrm{H}$ & 29.6466 & -40.1441 & -1.9019 \\
$\mathrm{H}$ & 29.0506 & -40.1097 & -0.4687 \\
$\mathrm{O}$ & 27.7083 & -40.3069 & 0.6051 \\
$\mathrm{H}$ & 27.6403 & -39.4409 & 1.0439 \\
$\mathrm{H}$ & 26.8649 & -40.3743 & 0.1095 \\
$\mathrm{O}$ & 25.3507 & -40.1183 & -0.9006 \\
$\mathrm{H}$ & 24.5083 & -40.4902 & -0.6120 \\
$\mathrm{H}$ & 25.2501 & -39.1476 & -0.7875 \\
$\mathrm{O}$ & 25.3917 & -37.3962 & -0.3791 \\
$\mathrm{H}$ & 25.5108 & -36.7584 & -1.0937 \\
$\mathrm{H}$ & 26.1882 & -37.2944 & 0.1837 \\
$\mathrm{O}$ & 27.6626 & -37.4465 & 1.2384 \\
$\mathrm{H}$ & 27.7398 & -36.9721 & 2.0750 \\
$\mathrm{H}$ & 28.4945 & -37.2512 & 0.7373 \\
\hline & & & \\
\hline
\end{tabular}

$\begin{array}{llll}\mathrm{H} & -28.4945 & -37.2512 & 0.7373\end{array}$

$\begin{array}{llll}18 & & & \\ 6-\mathrm{CC} & & & \\ \mathrm{O} & -0.1141 & -45.4756 & 0.4357 \\ \mathrm{H} & -0.1212 & -45.0081 & 1.2795 \\ \mathrm{H} & -0.9900 & -45.9275 & 0.3939 \\ \mathrm{O} & -2.6533 & -49.4119 & 0.4391\end{array}$




$$
\begin{array}{lllll}
\mathrm{H} & & -1.8471 & -49.9163 & 0.1772 \\
\mathrm{H} & -2.9576 & -49.8399 & 1.2483 \\
\mathrm{O} & 2.1002 & -46.9006 & -0.2471 \\
\mathrm{H} & 2.4044 & -46.4744 & -1.0573 \\
\mathrm{H} & & 1.2956 & -46.3941 & 0.0156 \\
\mathrm{O} & -0.4370 & -50.8340 & -0.2436 \\
\mathrm{H} & 0.4396 & -50.3836 & -0.2009 \\
\mathrm{H} & -0.4308 & -51.2999 & -1.0883 \\
\mathrm{O} & 1.9963 & -49.6175 & -0.1859 \\
\mathrm{H} & 2.6080 & -49.8611 & 0.5191 \\
\mathrm{H} & 2.0244 & -48.6317 & -0.2130 \\
\mathrm{O} & -2.5466 & -46.6945 & 0.3830 \\
\mathrm{H} & -3.1568 & -46.4524 & -0.3238 \\
\mathrm{H} & -2.5749 & -47.6802 & 0.4115
\end{array}
$$




$\begin{array}{llll}\mathrm{H} & 10.0613 & -50.5472 & -1.9320 \\ \mathrm{H} & 9.4474 & -50.4883 & -0.5041 \\ \mathrm{O} & 8.2958 & -48.9198 & 2.5834 \\ \mathrm{H} & 7.7974 & -48.8686 & 3.4078 \\ \mathrm{H} & 7.9420 & -48.2014 & 2.0231 \\ \mathrm{O} & 6.1151 & -49.3715 & -0.6444 \\ \mathrm{H} & 6.4601 & -48.5223 & -0.3019 \\ \mathrm{H} & 5.1679 & -49.3538 & -0.4625\end{array}$

18

6-CB-1

$\begin{array}{llll}\text { O } & 18.0712 & -51.4753 & 1.0577\end{array}$

H $\quad 18.3158 \quad-52.4080 \quad 1.0702$

$\mathrm{H} \quad 18.9200 \quad-50.9885 \quad 0.9316$

O $\quad 20.4013 \quad-50.1151 \quad 0.6787$

H $\quad 20.3203 \quad-49.3282 \quad 0.0893$

H $\quad 20.8628 \quad-49.7855 \quad 1.4593$

O $\quad 20.1820-47.9418 \quad-0.9528$

H $\quad 19.3727 \quad-47.3927 \quad-0.8299$

H $\quad 20.2353 \quad-48.1019 \quad-1.9024$

O $\quad 15.8359 \quad-50.5064 \quad-0.1649$

H $\quad 15.7879 \quad-50.8915 \quad-1.0479$

H $\quad 16.6469 \quad-50.8938 \quad 0.2396$

O $\quad 17.9552-46.4504 \quad-0.4572$

H $\quad 17.7010-45.6711 \quad-0.9652$

H $\quad 17.1102-46.9274 \quad-0.2792$

O $\quad 15.6330 \quad-47.7931 \quad 0.0179$ 
$\begin{array}{llll}\mathrm{H} & 15.7046 & -48.7745 & -0.0499 \\ \mathrm{H} & 15.1884 & -47.6406 & 0.8605\end{array}$

18

6-CB-2

$\begin{array}{llll}\text { O } & 26.0243 & -46.8132 & 0.6983\end{array}$

H $\quad 25.9101 \quad-46.6716 \quad 1.6460$

H $\quad 26.0029-47.7919 \quad 0.5870$

O $\quad 26.0716-49.5194 \quad 0.3763$

$\mathrm{H} \quad 26.7867 \quad-49.9034 \quad-0.1830$

$\begin{array}{llll}\mathrm{H} & 25.3029 & -50.0816 & 0.2267\end{array}$

O $\quad 28.1035 \quad-50.5775 \quad-1.1078$

H $\quad 29.0003 \quad-50.2744 \quad-0.8287$

H $\quad 28.1161 \quad-50.5173 \quad-2.0704$

O $\quad 28.2510 \quad-45.6677 \quad-0.3766$

H $\quad 27.9994 \quad-45.4294 \quad-1.2768$

H $\quad 27.4402-46.0768 \quad 0.0100$

O $\quad 30.5786 \quad-49.7113 \quad-0.3571$

H $\quad 30.9359 \quad-50.1242 \quad 0.4385$

H $\quad 30.6024 \quad-48.7444 \quad-0.1688$

$\begin{array}{llll}\text { O } & 30.5444 & -47.0387 & 0.1802\end{array}$

H $\quad 29.7277 \quad-46.5346 \quad-0.0448$

H $\quad 31.2721 \quad-46.4282 \quad 0.0153$

21

7-PR1 


$\begin{array}{llll}\mathrm{O} & 1.3307 & -0.9981 & -1.5594 \\ \mathrm{H} & 1.8225 & -0.8772 & -2.3810 \\ \mathrm{H} & 0.3863 & -1.0622 & -1.8218 \\ \mathrm{O} & 1.2693 & 0.9748 & 0.5473 \\ \mathrm{H} & 1.4273 & 0.3555 & -0.1902 \\ \mathrm{H} & 0.8178 & 0.4228 & 1.2127 \\ \mathrm{O} & 0.1327 & -2.8611 & 0.3497 \\ \mathrm{H} & -0.5745 & -2.6787 & -0.2979 \\ \mathrm{H} & 0.9184 & -2.5580 & -0.1351 \\ \mathrm{O} & -0.3721 & -0.8388 & 2.0915 \\ \mathrm{H} & -0.3693 & -1.0911 & 3.0228 \\ \mathrm{H} & -0.1659 & -1.6650 & 1.5874 \\ \mathrm{O} & -2.2676 & 0.2535 & 0.2101 \\ \mathrm{H} & -1.8893 & 1.1445 & 0.0408 \\ \mathrm{H} & -1.7965 & -0.0502 & 1.0079 \\ \mathrm{O} & -0.8028 & 2.5498 & -0.2993 \\ \mathrm{H} & -0.8087 & 3.3772 & 0.1965 \\ \mathrm{H} & 0.0294 & 2.0926 & -0.0283 \\ \mathrm{O} & -1.3901 & -1.4527 & -1.6147 \\ \mathrm{H} & -2.0522 & -1.6159 & -2.2970 \\ \mathrm{H} & -1.8023 & -0.7893 & -0.9884\end{array}$

21

7-PR2

O $\quad 12.1988 \quad-0.5958 \quad-1.4694$

$\mathrm{H} \quad \begin{array}{llll}12.3997 & -1.3259 & -0.8578\end{array}$

$\mathrm{H} \quad 12.4697 \quad 0.1962 \quad-0.9698$ 


\begin{tabular}{llll}
$\mathrm{O}$ & 9.5826 & -1.3710 & -0.8206 \\
$\mathrm{H}$ & 10.3679 & -0.9785 & -1.2620 \\
$\mathrm{H}$ & 10.0106 & -2.0699 & -0.2940 \\
$\mathrm{O}$ & 11.4429 & -0.1966 & 2.1649 \\
$\mathrm{H}$ & 11.9472 & 0.4816 & 1.6763 \\
$\mathrm{H}$ & 10.5160 & 0.0558 & 1.9996 \\
$\mathrm{O}$ & 10.1038 & 2.7293 & -0.1100 \\
$\mathrm{H}$ & 9.5621 & 2.0062 & 0.2782 \\
$\mathrm{H}$ & 9.7829 & 2.8149 & -1.0167 \\
$\mathrm{O}$ & 8.8968 & 0.4835 & 0.9527 \\
$\mathrm{H}$ & 7.9728 & 0.4042 & 1.2197 \\
$\mathrm{H}$ & 9.0509 & -0.2338 & 0.2735 \\
$\mathrm{O}$ & 12.5694 & 1.6669 & 0.2883 \\
$\mathrm{H}$ & 11.7478 & 2.1847 & 0.1078 \\
$\mathrm{H}$ & 13.2740 & 2.3184 & 0.3885 \\
$\mathrm{O}$ & 11.7451 & -2.4764 & 0.7183 \\
$\mathrm{H}$ & 11.6903 & -1.7175 & 1.3515 \\
$\mathrm{H}$ & 12.1222 & -3.2087 & 1.2202 \\
\hline
\end{tabular}

21

7-PR3

$\begin{array}{llll}\text { O } & 20.2737 & 0.1767 & 0.0767\end{array}$

$\mathrm{H} \quad 20.7207 \quad 0.0108 \quad 0.9277$

H $\quad 20.5607 \quad 1.0857 \quad-0.1569$

O $\quad 24.0486 \quad-0.9689 \quad-1.4628$

H $\quad 23.1226 \quad-1.1600 \quad-1.7263$

H $\quad 24.5479 \quad-0.9068 \quad-2.2862$ 


$$
\begin{array}{llll}
\mathrm{O} & 22.9166 & -2.6456 & 0.6998 \\
\mathrm{H} & 22.2494 & -2.5690 & -0.0094 \\
\mathrm{H} & 23.7267 & -2.3793 & 0.2361 \\
\mathrm{O} & 22.1630 & -0.4709 & 2.1515 \\
\mathrm{H} & 22.1224 & -0.5891 & 3.1082 \\
\mathrm{H} & 22.4624 & -1.3376 & 1.7826 \\
\mathrm{O} & 23.7435 & 1.2189 & 0.4040 \\
\mathrm{H} & 23.9457 & 0.5253 & -0.2514 \\
\mathrm{H} & 23.3384 & 0.7250 & 1.1407 \\
\mathrm{O} & 21.3767 & -1.6453 & -1.4808 \\
\mathrm{H} & 20.8894 & -0.9379 & -0.9639 \\
\mathrm{H} & 20.7369 & -2.0040 & -2.1073 \\
\mathrm{O} & 21.5194 & 2.6165 & -0.3655 \\
\mathrm{H} & 21.6501 & 3.2036 & -1.1188 \\
\mathrm{H} & 22.4079 & 2.2402 & -0.1601
\end{array}
$$

21

7-CA 1

$$
\begin{array}{llll}
\mathrm{O} & 32.9263 & 1.1237 & -1.1222 \\
\mathrm{H} & 32.1132 & 0.5788 & -1.0572 \\
\mathrm{H} & 33.6283 & 0.4669 & -1.2805 \\
\mathrm{O} & 34.2477 & -0.0936 & 2.6177 \\
\mathrm{H} & 34.1015 & -0.0685 & 3.5711 \\
\mathrm{H} & 33.8912 & 0.7630 & 2.2628 \\
\mathrm{O} & 36.5153 & -0.3922 & 1.0549 \\
\mathrm{H} & 35.8012 & -0.3357 & 1.7268 \\
\mathrm{H} & 36.9724 & 0.4558 & 1.1173
\end{array}
$$




$\begin{array}{llll}\mathrm{O} & 30.8784 & -0.6349 & -0.4421 \\ \mathrm{H} & 30.3427 & -1.2671 & -0.9355 \\ \mathrm{H} & 31.5176 & -1.1824 & 0.0702 \\ \mathrm{O} & 33.3275 & 2.0677 & 1.3588 \\ \mathrm{H} & 33.1384 & 1.7593 & 0.4316 \\ \mathrm{H} & 33.7342 & 2.9362 & 1.2603 \\ \mathrm{O} & 34.9425 & -0.9679 & -1.0989 \\ \mathrm{H} & 35.6331 & -0.7601 & -0.4261 \\ \mathrm{H} & 35.4007 & -1.4404 & -1.8046 \\ \mathrm{O} & 32.9653 & -1.9667 & 0.7668 \\ \mathrm{H} & 33.6384 & -1.8132 & 0.0782 \\ \mathrm{H} & 33.3084 & -1.4551 & 1.5218\end{array}$

21

7-CA2

O $\quad-2.5823 \quad-13.3214 \quad-0.0909$

$\mathrm{H} \quad-3.4235 \quad-13.5467 \quad 0.3217$

$\mathrm{H} \quad-1.9000 \quad-13.4106 \quad 0.6127$

O $\quad 0.4246 \quad-10.6343 \quad 2.2823$

$\mathrm{H} \quad 0.6341 \quad-10.2876 \quad 3.1584$

H $\quad 1.2967 \quad-10.7196 \quad 1.8215$

O $\quad \begin{array}{llll}-1.2230 & -9.2715 & 0.4204\end{array}$

$\begin{array}{llll}\mathrm{H} & -2.0817 & -9.1013 & 0.8269\end{array}$

$\mathrm{H} \quad \begin{array}{llll}-0.6736 & -9.6390 & 1.1419\end{array}$

O $\quad-1.1393 \quad-11.3684 \quad-1.4714$

$\mathrm{H} \quad-1.8150 \quad-11.9710 \quad-1.1005$

$\mathrm{H} \quad \begin{array}{llll}-1.2066 & -10.5695 & -0.9089\end{array}$ 


$\begin{array}{llll}\mathrm{O} & -0.3356 & -13.3572 & 1.5000 \\ \mathrm{H} & 0.2531 & -13.3345 & 0.7229 \\ \mathrm{H} & -0.1843 & -12.4884 & 1.9138 \\ \mathrm{O} & 2.6513 & -11.1407 & 0.8153 \\ \mathrm{H} & 2.2222 & -11.6676 & 0.1021 \\ \mathrm{H} & 3.3128 & -11.7340 & 1.1926 \\ \mathrm{O} & 1.1139 & -12.6242 & -0.9048 \\ \mathrm{H} & 1.4107 & -13.0941 & -1.6937 \\ \mathrm{H} & 0.2929 & -12.1216 & -1.1894\end{array}$

7-CH1

O $\quad 10.7209 \quad-13.2826 \quad-0.5077$

$\mathrm{H} \quad 10.9950 \quad-13.7579 \quad-1.3021$

H $\quad 11.4246 \quad-13.4796 \quad 0.1632$

O $\quad 8.0071-13.1885 \quad 0.1152$

H $\quad 8.9620 \quad-13.3362 \quad-0.0531$

$\mathrm{H} \quad 7.8114 \quad-13.6934 \quad 0.9137$

O $\quad 7.7951-10.4206 \quad 0.0176$

H $\quad 7.7357 \quad-11.3989 \quad 0.0744$

H $\quad 7.1607 \quad-10.1753 \quad-0.6671$

O $\quad 10.5405 \quad-10.3857 \quad-0.6089$

$\mathrm{H} \quad 9.5901 \quad-10.2738 \quad-0.3987$

H $\quad 10.6494-11.3528 \quad-0.6574$

$\begin{array}{llll}\text { O } & 12.3067 & -9.3516 & 1.1569\end{array}$

H $\quad \begin{array}{llll}11.6382 & -9.6811 & 0.5032\end{array}$

$\begin{array}{llll}\mathrm{H} & 11.7931 & -8.8595 & 1.8087\end{array}$ 


$\begin{array}{llll}\mathrm{O} & 13.8461 & -11.4044 & 1.9949 \\ \mathrm{H} & 13.2992 & -10.6268 & 1.7175 \\ \mathrm{H} & 14.7353 & -11.2062 & 1.6772 \\ \mathrm{O} & 12.6841 & -13.7257 & 1.2646 \\ \mathrm{H} & 13.1382 & -12.8874 & 1.5330 \\ \mathrm{H} & 12.5400 & -14.2052 & 2.0891\end{array}$

21

7-CH2

$\begin{array}{llll}\text { O } & 19.6044 & -9.9523 & 1.3350\end{array}$

$\mathrm{H} \quad 19.8828 \quad-9.7915 \quad 2.2451$

H $\quad 19.4156 \quad-10.9148 \quad 1.3024$

O $\quad 23.8120 \quad-13.2474 \quad 1.0098$

$\mathrm{H} \quad 23.6336-13.6091 \quad 1.8867$

$\mathrm{H} \quad 24.3380-12.4255 \quad 1.1763$

O $\quad 19.4156-12.7102 \quad 1.0133$

H $\quad 20.1583-12.8812 \quad 0.3962$

$\mathrm{H} \quad 18.6484 \quad-13.1302 \quad 0.6058$

$\begin{array}{llll}\text { O } & 23.9595 & -8.9735 & 0.0628\end{array}$

H $\quad 23.0822 \quad-9.3089 \quad-0.2561$

$\begin{array}{llll}\mathrm{H} & 23.7740 & -8.0994 & 0.4257\end{array}$

O $\quad 21.5586 \quad-9.9519 \quad-0.7030$

H $\quad 20.8708 \quad-9.8426 \quad-0.0139$

H $\quad 21.6266-10.9195 \quad-0.7973$

O $\quad 21.6966-12.8480 \quad-0.5885$

H $\quad 21.8359-13.3944 \quad-1.3719$

H $\quad 22.4823 \quad-13.0249 \quad-0.0071$ 


$$
\begin{aligned}
& \begin{array}{llll}
\text { O } & 25.1853 & -10.9532 & 1.4419
\end{array} \\
& \text { H } \quad 26.0843 \quad-10.9216 \quad 1.0921 \\
& \text { H } \quad 24.7220 \quad-10.2044 \quad 0.9913 \\
& 21 \\
& \text { 7-BI1 } \\
& \text { O } \quad 33.3720 \quad-11.1043 \quad 0.5750 \\
& \begin{array}{llll}
\mathrm{H} & 32.9397 & -11.8110 & 0.0398
\end{array} \\
& \text { H } \quad 33.9392 \quad-11.5913 \quad 1.2184 \\
& \begin{array}{llll}
\text { O } & 29.5528 & -11.9264 & 0.1297
\end{array} \\
& \begin{array}{llll}
H & 28.9927 & -12.4068 & 0.7517
\end{array} \\
& \text { H } \quad 29.9604-11.2069 \quad 0.6648 \\
& \begin{array}{llll}
\text { O } & 31.0117 & -10.1260 & 1.6019
\end{array} \\
& \text { H } \quad 31.9201 \quad-10.3828 \quad 1.3176 \\
& \begin{array}{llll}
\mathrm{H} & 30.9756 & -9.1676 & 1.4977
\end{array} \\
& \begin{array}{llll}
\text { O } & 35.5100 & -10.1278 & -0.8697
\end{array} \\
& \text { H } \quad 34.6745 \quad-10.3715 \quad-0.4064 \\
& \text { H } \quad 35.5906 \quad-9.1735 \quad-0.7531 \\
& \begin{array}{llll}
\text { O } & 31.9133 & -12.9908 & -0.7832
\end{array} \\
& \text { H } \quad 31.9020 \quad-13.0234 \quad-1.7477 \\
& \text { H } \quad 31.0017 \quad-12.7212 \quad-0.5246 \\
& \begin{array}{llll}
\text { O } & 37.1208 & -12.0101 & 0.3627
\end{array} \\
& \text { H } \quad 38.0184-11.6971 \quad 0.5257 \\
& \text { H } \quad 36.6838 \quad-11.2926 \quad-0.1487 \\
& \begin{array}{llll}
\text { O } & 35.1142 & -12.5169 & 2.1780
\end{array} \\
& \begin{array}{llll}
\mathrm{H} & 35.9308 & -12.3927 & 1.6437
\end{array} \\
& \text { H } \quad 34.9571 \quad-13.4696 \quad 2.1636
\end{aligned}
$$




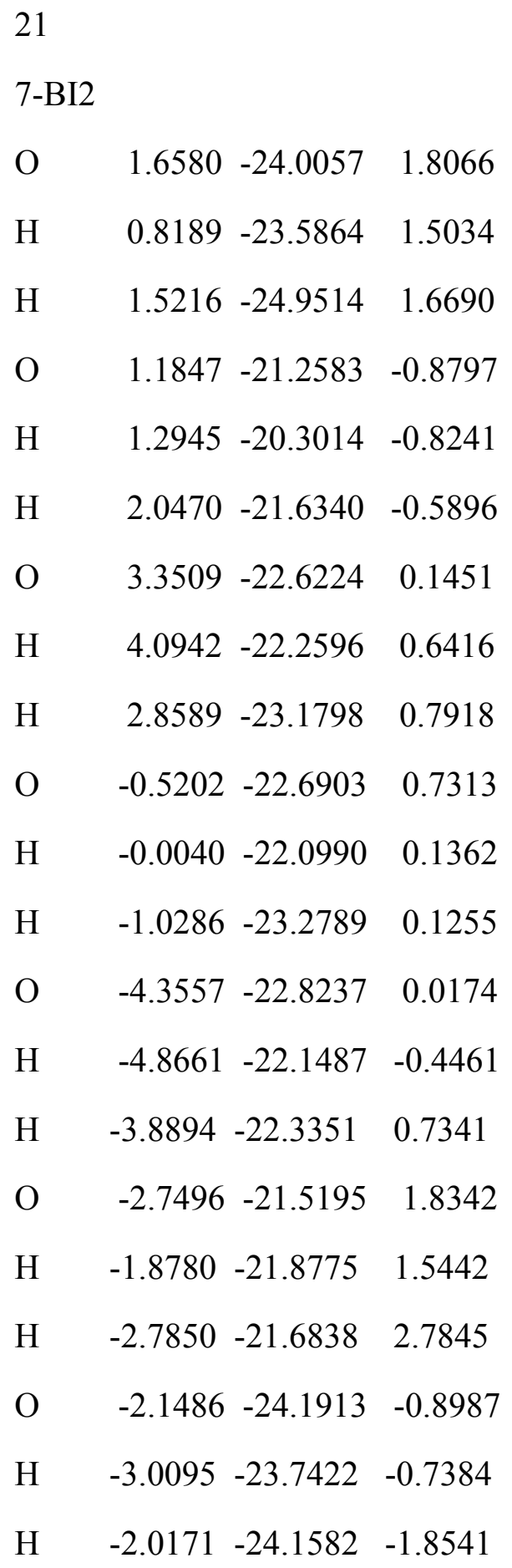

21

7-CH3 


\begin{tabular}{|c|c|c|c|}
\hline $\mathrm{O}$ & 7.5321 & -24.1990 & 0.4989 \\
\hline & 7.0601 & -24.6904 & 1.1826 \\
\hline & 7.3725 & -23.2562 & 0.7178 \\
\hline & 7.5072 & -21.4628 & 1.0574 \\
\hline & 8.4277 & -21.1920 & 0.8644 \\
\hline & 6.9579 & -20.7943 & 0.6309 \\
\hline $\mathrm{O}$ & 10.3259 & -23.8389 & 0.7583 \\
\hline & 9.4046 & -24.1454 & 0.6407 \\
\hline & 10.2750 & -22.8826 & 0.5758 \\
\hline $\mathrm{O}$ & 14.1438 & -22.4267 & 0.7932 \\
\hline $\mathrm{H}$ & 14.8360 & -22.2869 & 0.1357 \\
\hline Г & 13.6797 & -23.2499 & 0.5008 \\
\hline $\mathrm{O}$ & 12.5147 & -20.3343 & 1.3690 \\
\hline $\mathrm{H}$ & 12.5982 & -20.1697 & 2.3162 \\
\hline $\mathrm{H}$ & 13.1320 & -21.0843 & 1.1843 \\
\hline$U$ & 10.1606 & -21.0055 & 0.2673 \\
\hline $\mathrm{H}$ & 10.2930 & -20.7699 & -0.6596 \\
\hline $\mathrm{H}$ & 10.9866 & -20.7011 & 0.7247 \\
\hline $\mathrm{O}$ & 12.7750 & -24.6328 & -0.0252 \\
\hline $\mathrm{H}$ & 12.9643 & -25.4452 & 0.4604 \\
\hline 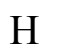 & 11.8280 & -24.4369 & 0.1842 \\
\hline
\end{tabular}

21

7-HM1

O $\quad 21.6750 \quad-19.9098 \quad-0.0709$

H $\quad 22.4466-20.4863 \quad-0.2962$

H $\quad 21.6556 \quad-19.2430 \quad-0.7678$ 


\begin{tabular}{llll}
$\mathrm{O}$ & 25.4199 & -22.9313 & 1.1871 \\
$\mathrm{H}$ & 25.3107 & -22.9684 & 2.1451 \\
$\mathrm{H}$ & 24.7996 & -23.5989 & 0.8358 \\
$\mathrm{O}$ & 23.7558 & -21.5168 & -0.7148 \\
$\mathrm{H}$ & 23.4975 & -22.4521 & -0.8110 \\
$\mathrm{H}$ & 24.4667 & -21.5879 & -0.0534 \\
$\mathrm{O}$ & 21.2141 & -25.5025 & 0.1691 \\
$\mathrm{H}$ & 21.0852 & -26.0097 & 0.9793 \\
$\mathrm{H}$ & 20.4392 & -24.8909 & 0.1266 \\
$\mathrm{O}$ & 19.0829 & -23.8388 & 0.0735 \\
$\mathrm{H}$ & 18.4968 & -23.8760 & -0.6917 \\
$\mathrm{H}$ & 19.2056 & -22.8755 & 0.2514 \\
$\mathrm{O}$ & 23.5841 & -24.3688 & -0.4313 \\
$\mathrm{H}$ & 22.7286 & -24.8050 & -0.1925 \\
$\mathrm{H}$ & 23.9609 & -24.9243 & -1.1250 \\
$\mathrm{O}$ & 19.3655 & -21.1846 & 0.5605 \\
$\mathrm{H}$ & 20.2035 & -20.7230 & 0.3152 \\
$\mathrm{H}$ & 19.1639 & -20.8709 & 1.4501 \\
\hline
\end{tabular}

24

8-S4

H $\quad-0.5694 \quad-36.2049 \quad 0.6946$

$\begin{array}{llll}\text { O } & 1.0827 & -36.2700 & 1.0659\end{array}$

H $\quad 1.2286 \quad-35.6126 \quad 1.7736$

H $\quad 2.8761 \quad-34.7794 \quad-1.6403$

O $\quad 1.1118-33.9925 \quad 2.7859$

O $\quad-1.4977 \quad-35.9456 \quad 0.4446$ 


$$
\begin{array}{llll}
\mathrm{H} & -2.0202 & -36.7562 & 0.4761 \\
\mathrm{H} & -1.0781 & -34.9196 & -1.1009 \\
\mathrm{H} & -1.6495 & -34.3907 & 1.5452 \\
\mathrm{O} & -1.4129 & -33.5680 & 2.0159 \\
\mathrm{H} & -1.3379 & -32.9062 & 1.3009 \\
\mathrm{H} & 0.1444 & -33.8118 & 2.6339 \\
\mathrm{O} & 1.9548 & -32.5727 & 0.4713 \\
\mathrm{O} & -0.6783 & -34.2499 & -1.6895 \\
\mathrm{H} & 0.2695 & -34.4867 & -1.6977 \\
\mathrm{H} & -1.1794 & -31.2578 & -0.7031 \\
\mathrm{O} & 2.0722 & -34.7246 & -1.1095 \\
\mathrm{H} & 1.5594 & -35.8936 & 0.3004 \\
\mathrm{H} & 2.1541 & -33.8915 & -0.5700 \\
\mathrm{H} & 1.7997 & -32.9353 & 1.3654 \\
\mathrm{H} & 1.2626 & -33.8631 & 3.7301 \\
\mathrm{O} & -0.7408 & -31.9930 & -0.2581 \\
\mathrm{H} & -0.7830 & -32.7621 & -0.8893 \\
\mathrm{H} & 1.0988 & -32.1648 & 0.2364 \\
\hline
\end{array}
$$




\begin{tabular}{lllll}
$\mathrm{O}$ & 11.6630 & -33.9016 & 2.7981 \\
$\mathrm{H}$ & 10.9827 & -34.2621 & -1.7079 \\
$\mathrm{H}$ & 12.8047 & -33.7471 & -0.4799 \\
$\mathrm{H}$ & 13.5482 & -34.6525 & -1.5203 \\
$\mathrm{H}$ & 8.1941 & -36.1383 & 0.4216 \\
$\mathrm{H}$ & 9.5847 & -34.6555 & -1.2001 \\
$\mathrm{H}$ & 8.8875 & -34.8335 & 0.9426 \\
$\mathrm{H}$ & 12.0282 & -34.0665 & 3.6759 \\
$\mathrm{H}$ & 9.8566 & -33.4895 & 2.3591 \\
$\mathrm{H}$ & 12.3933 & -32.7887 & 1.4370 \\
$\mathrm{O}$ & 9.0265 & -33.4063 & 1.8507 \\
$\mathrm{H}$ & 9.9264 & -32.5196 & -0.9299 \\
$\mathrm{H}$ & 11.7563 & -31.9929 & 0.2838 \\
$\mathrm{O}$ & 12.5930 & -32.4179 & 0.5556 \\
$\mathrm{H}$ & 9.2145 & -32.6946 & 1.2084 \\
$\mathrm{O}$ & 9.9522 & -31.7644 & -0.2815 \\
$\mathrm{O}$ & 10.0436 & -33.9979 & -1.7581 \\
$\mathrm{H}$ & 9.5766 & -31.0040 & -0.7418 \\
\hline
\end{tabular}

27

9-D2dDD

H $\quad 0.9939-47.5073 \quad 1.0498$

$\begin{array}{llll}\text { O } & 2.4840 & -47.2556 & 0.2919\end{array}$

$\mathrm{H} \quad 2.8569 \quad-46.4716 \quad 0.7405$

H $\quad 2.2706 \quad-46.9299 \quad-0.6043$

O $\quad 2.9669 \quad-44.7598 \quad 1.5636$

O $\quad \begin{array}{llll}1.4291 & -45.9286 & -1.9917\end{array}$ 


\begin{tabular}{llll}
$\mathrm{O}$ & 0.0851 & -47.4532 & 1.4548 \\
$\mathrm{H}$ & 2.7383 & -43.8524 & -0.0667 \\
$\mathrm{H}$ & 2.0717 & -44.7262 & 1.9988 \\
$\mathrm{H}$ & 3.5997 & -44.5034 & 2.2455 \\
$\mathrm{H}$ & 1.3333 & -46.1705 & -2.9209 \\
$\mathrm{H}$ & 2.1872 & -44.3007 & -1.4311 \\
$\mathrm{H}$ & 0.5061 & -45.9050 & -1.6198 \\
$\mathrm{H}$ & -0.0997 & -48.3291 & 1.8146 \\
$\mathrm{H}$ & -0.7677 & -46.5603 & 0.0101 \\
$\mathrm{H}$ & 0.2547 & -45.8109 & 2.3850 \\
$\mathrm{O}$ & -0.9292 & -45.9329 & -0.7207 \\
$\mathrm{H}$ & -0.6609 & -42.8149 & 0.3146 \\
$\mathrm{H}$ & -0.1291 & -44.3464 & 2.0978 \\
$\mathrm{O}$ & 0.5035 & -44.8920 & 2.6050 \\
$\mathrm{H}$ & -1.1149 & -45.0869 & -0.2676 \\
$\mathrm{O}$ & -1.1895 & -43.5188 & 0.7745 \\
$\mathrm{O}$ & 2.4736 & -43.5054 & -0.9407 \\
$\mathrm{H}$ & -2.0551 & -43.1244 & 0.9375 \\
$\mathrm{O}$ & 0.3832 & -41.8489 & -0.6036 \\
$\mathrm{H}$ & 1.1744 & -42.4245 & -0.7780 \\
\hline & 0.7478 & -41.0117 & -0.2928 \\
\hline
\end{tabular}

27

9-S4DA

$\begin{array}{llll}\text { O } & 11.2757 & -44.8859 & 2.5396\end{array}$

$\mathrm{H} \quad 11.2326 \quad-45.8344 \quad 2.3090$

H $\quad 10.4838-44.5098 \quad 2.1092$ 


\begin{tabular}{|c|c|c|c|}
\hline $\mathrm{O}$ & 10.3650 & -41.7291 & -0.4330 \\
\hline $\mathrm{H}$ & 9.8631 & -42.4364 & 0.0253 \\
\hline $\mathrm{H}$ & 10.3700 & -40.9863 & 0.1829 \\
\hline $\mathrm{O}$ & 12.7249 & -43.0483 & -1.1189 \\
\hline & 13.1076 & -43.2843 & -0.2520 \\
\hline $\mathrm{H}$ & 11.9396 & -42.5041 & -0.8976 \\
\hline $\mathrm{O}$ & 9.1887 & -43.9265 & 0.8265 \\
\hline $\mathrm{H}$ & 9.3643 & -44.7086 & 0.2287 \\
\hline $\mathrm{H}$ & 8.2371 & -43.9436 & 0.9899 \\
\hline $\mathrm{O}$ & 9.8384 & -46.0441 & -0.6354 \\
\hline $\mathrm{H}$ & 10.5460 & -45.8440 & -1.2820 \\
\hline $\mathrm{H}$ & 10.2567 & -46.6716 & -0.0146 \\
\hline $\mathrm{O}$ & 12.1168 & -45.4025 & -2.1680 \\
\hline $\mathrm{H}$ & 12.2443 & -45.4171 & -3.1243 \\
\hline 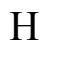 & 12.3321 & -44.4708 & -1.8772 \\
\hline $\mathrm{O}$ & 13.5438 & -46.6304 & -0.0384 \\
\hline 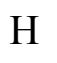 & 13.7753 & -45.8040 & 0.4286 \\
\hline $\mathrm{H}$ & 13.1851 & -46.3179 & -0.8925 \\
\hline $\mathrm{O}$ & 13.5721 & -44.1460 & 1.3622 \\
\hline$\Pi$ & 12.7238 & -44.3391 & 1.8449 \\
\hline $\mathrm{H}$ & 14.1737 & -43.7877 & 2.0261 \\
\hline $\mathrm{O}$ & 11.3879 & -47.4448 & 1.3012 \\
\hline 11 & 11.4285 & -48.3650 & 1.5880 \\
\hline $\mathrm{H}$ & 12.2469 & -47.2637 & 0.8295 \\
\hline
\end{tabular}




$$
\begin{aligned}
& \text { O } \quad 24.4741 \quad-43.1071 \quad-0.9246 \\
& \text { H } \quad 24.9624-42.5211 \quad-1.5156 \\
& \mathrm{H} \quad 23.6137 \quad-42.6570 \quad-0.7533 \\
& \text { O } \quad 24.0533 \quad-45.8936 \quad-1.3438 \\
& \mathrm{H} \quad 24.2332 \quad-44.9340 \quad-1.3169 \\
& \text { H } \quad 24.4239-46.2302 \quad-0.5035 \\
& \begin{array}{llll}
\text { O } & 22.0435 & -42.1095 & -0.1487
\end{array} \\
& \text { H } \quad 21.5896 \quad-41.3334 \quad-0.5001 \\
& \text { H } \quad 21.3774 \quad-42.8544 \quad-0.2098 \\
& \begin{array}{llll}
\text { O } & 21.4582 & -46.4782 & -1.1217
\end{array} \\
& \text { H } \quad 22.4108 \quad-46.2331 \quad-1.2825 \\
& \text { H } \quad 21.1934 \quad-47.0088 \quad-1.8829 \\
& \text { O } \quad 24.6257 \quad-46.7092 \quad 1.3021 \\
& \text { H } \quad 23.6726 \quad-46.9151 \quad 1.5072 \\
& \text { H } \quad 25.1364 \quad-47.4473 \quad 1.6560 \\
& \begin{array}{llll}
\text { O } & 22.0089 & -47.1369 & 1.6064
\end{array} \\
& \text { H } \quad 21.5538 \quad-46.3956 \quad 2.0554 \\
& \text { H } \quad 21.6865 \quad-47.0889 \quad 0.6865 \\
& \begin{array}{llll}
\text { O } & 22.6317 & -42.9029 & 2.5986
\end{array} \\
& \text { H } \quad 22.4408 \quad-42.4020 \quad 1.7857 \\
& \text { H } \quad 23.5321 \quad-43.2690 \quad 2.4302 \\
& \begin{array}{llll}
\text { O } & 20.7792 & -44.7972 & 2.5703
\end{array} \\
& \text { H } \quad 20.2487 \quad-44.7048 \quad 3.3710 \\
& \text { H } \quad 21.5043 \quad-44.1120 \quad 2.6482 \\
& \text { O } \quad 20.3101 \quad-44.1126 \quad-0.1300 \\
& \text { H } \quad 20.6293 \quad-44.9134 \quad-0.5935 \\
& \text { H } \quad 20.2687 \quad-44.3819 \quad 0.8093
\end{aligned}
$$


$\begin{array}{llll}\mathrm{O} & 25.0617 & -43.9393 & 1.8033 \\ \mathrm{H} & 25.0027 & -44.9109 & 1.7219 \\ \mathrm{H} & 25.0729 & -43.6284 & 0.8809\end{array}$

30

10-PP2

$\begin{array}{llll}\text { O } & 32.6179 & -46.8626 & 2.3475\end{array}$

H $\quad 32.2757 \quad-47.1376 \quad 1.4783$

$\begin{array}{llll}\mathrm{H} & 32.1520 & -46.0073 & 2.5042\end{array}$

$\begin{array}{llll}\text { O } & 31.8446 & -47.0712 & -0.4498\end{array}$

H $\quad 31.3260 \quad-46.2341 \quad-0.5051$

H $\quad 31.3269 \quad-47.7297 \quad-0.9289$

$\begin{array}{llll}\text { O } & 34.6287 & -46.6132 & -0.8546\end{array}$

H $\quad 33.6750 \quad-46.8201 \quad-0.8082$

$\begin{array}{llll}\text { H } & 34.9409 & -46.7333 & 0.0643\end{array}$

$\begin{array}{llll}\text { O } & 32.6163 & -42.8301 & -0.7584\end{array}$

H $\quad 33.4604-43.1963 \quad-1.0912$

$\begin{array}{llll}\mathrm{H} & 32.8373 & -42.5122 & 0.1398\end{array}$

$\begin{array}{llll}\text { O } & 35.0983 & -44.0369 & -1.3330\end{array}$

H $\quad 34.9147 \quad-45.0131-1.2485$

H $\quad 35.6657 \quad-43.9436 \quad-2.1079$

$\begin{array}{llll}\text { O } & 35.2063 & -46.5221 & 1.9176\end{array}$

H $\quad 35.7066 \quad-47.1062 \quad 2.5003$

H $\quad 34.2465 \quad-46.6437 \quad 2.1724$

$\begin{array}{llll}\text { O } & 30.6822 & -44.5942 & -0.4005\end{array}$

H $\quad 31.3899 \quad-43.9202 \quad-0.6163$

H $\quad 29.8921 \quad-44.2993 \quad-0.8697$ 


$\begin{array}{llll}\mathrm{O} & 35.5854 & -43.7624 & 1.4744 \\ \mathrm{H} & 35.5480 & -44.7070 & 1.7282 \\ \mathrm{H} & 35.6177 & -43.7847 & 0.4990 \\ \mathrm{O} & 33.3224 & -42.4399 & 1.9495 \\ \mathrm{H} & 33.5134 & -41.6471 & 2.4653 \\ \mathrm{H} & 34.1896 & -42.9251 & 1.8711 \\ \mathrm{O} & 31.3346 & -44.4228 & 2.4536 \\ \mathrm{H} & 30.9152 & -44.4148 & 1.5751 \\ \mathrm{H} & 31.9831 & -43.6939 & 2.4037\end{array}$

